\title{
ADVANCES IN ORAL TRANSMUCOSAL DRUG DELIVERY
}

\author{
Viralkumar F. Patel ${ }^{1}$, Fang Liu ${ }^{1}$, Marc B. Brown ${ }^{1,2}$ \\ ${ }^{1}$ School of Pharmacy, University of Hertfordshire, Hatfield, UK AL10 9AB \\ ${ }^{2}$ MedPharm Limited, Guilford, Surrey, UK GU2 7YN
}

\begin{abstract}
The successful delivery of drugs across the oral mucosa represents a continuing challenge, as well as a great opportunity. Oral transmucosal delivery, especially buccal and sublingual delivery, has progressed far beyond the use of traditional dosage forms with novel approaches emerging continuously. This review highlights the physiological challenges as well as the advances and opportunities for buccal/sublingual drug delivery. Particular attention is given to new approaches which can extend dosage form retention time or can be engineered to deliver complex molecules such as proteins and peptides. The review will also provide a link between the physiology and local environment of the oral cavity in vivo and how this relates the performance of transmucosal delivery systems.
\end{abstract}

Keywords: Transmucosal, permeation pathways, buccal absorption, mucoadhesive, dosage forms

\section{Author for correspondence:}

Prof. Marc B. Brown

MedPharm Ltd

R\&D Centre

Unit 3 / Chancellor Court

50 Occam Road, Surrey Research Park,

Guildford, GU2 7YN, UK

Tel: +44 1483501480, Fax: +44 447742

E-mail: marc.brown@medpharm.co.uk 


\section{Contents}

1. Introduction

2. Overview of the oral mucosa

3. Physiological barriers for oral transmucosal drug delivery

4. Physiological opportunities for oral transmucosal drug delivery

5. Oral transmucosal drug delivery technologies

5.1 Mucoadhesive system

5.1.1 Theories of mucoadhesion

5.1.2 Polymers for mucoadhesive systems

5.2 Dosage forms

5.2.1 Liquid dosage forms

5.2.2 Semisolid dosage forms

5.2.3 Solid dosage forms

5.2.3.1 Tablets/lozenges

5.2.3.2 Patches/Films/Wafers

5.2.3.3 Micro/nano-particulates

5.2.4 Spray

6. Conclusion 


\section{Introduction}

The cost involved both in terms of money and time in the development of a single new chemical entity has made it mandatory for pharmaceutical companies to reconsider delivery strategies to improve the efficacy of drugs that have already been approved. However, despite the tremendous advances in drug delivery, the oral route remains the preferred route for the administration of therapeutic agents due to low cost, ease of administration and high level of patient compliance. However, significant barriers impose for the peroral administration of drugs, such as hepatic first pass metabolism and drug degradation within the gastrointestinal (GI) tract prohibiting the oral administration of certain classes of drugs especially biologics e.g. peptides and proteins. Consequently, other absorptive mucosae are being considered as potential sites for drug administration including the mucosal linings of the nasal, rectal, vaginal, ocular, and oral cavity. These transmucosal routes of drug delivery offer distinct advantages over peroral administration for systemic drug delivery such as possible bypass of the first pass effect and avoidance of presystemic elimination within the GI tract [1]. Amongst these, delivery of drugs to the oral cavity has attracted particular attention due to its potential for high patient compliance and unique physiological features. Within the oral mucosal cavity, the delivery of drugs is classified into two categories: (i) local delivery and (ii) systemic delivery either via the buccal or sublingual mucosa. This review examines the physiological considerations of the oral cavity in light of systemic drug delivery and provides an insight into the advances in oral transmucosal delivery systems.

\section{Overview of the oral mucosa}

The anatomical and physiological properties of oral mucosa had been extensively reviewed by several authors [1-3]. The oral cavity comprises the lips, cheek, tongue, hard palate, soft palate and floor of the mouth (Figure 1). The lining of the oral cavity is referred to as the oral mucosa, and includes the buccal, sublingual, gingival, palatal and labial mucosa. The buccal, sublingual and the mucosal tissues at the ventral surface of the tongue accounts for about $60 \%$ of the oral mucosal surface area. The top quarter to one-third of the oral mucosa is made up of closely compacted epithelial cells (Figure 2). The primary function of the oral epithelium is to protect the underlying tissue against potential harmful agents in the oral environment and from fluid loss [4]. Beneath the epithelium are the basement membrane, lamina propia and submucosa. The oral mucosa also contains many sensory receptors including the taste receptors of the tongue. 
Three types of oral mucosa can be found in the oral cavity; the lining mucosa is found in the outer oral vestibule (the buccal mucosa) and the sublingual region (floor of the mouth) (Figure 1). The specialised mucosa is found on the dorsal surface of tongue, while the masticatory mucosa is found on the hard palate (the upper surface of the mouth) and the gingiva (gums) [5]. The lining mucosa comprises approximately 60\%, the masticatory mucosa approximately $25 \%$, and the specialized mucosa approximately $15 \%$ of the total surface area of the oral mucosal lining in an adult human. The masticatory mucosa is located in the regions particularly susceptible to the stress and strains resulting from masticatory activity. The superficial cells of the masticatory mucosa are keratinized, and a thick lamina propia tightly binds the mucosa to underlying periosteum. Lining mucosa on the other hand is not nearly as subject to masticatory loads and consequently, has a non-keratinized epithelium, which sits on a thin and elastic lamina propia and a submucosa. The mucosa of the dorsum of the tongue is specialized gustatory mucosas, which has a well papillated surface; which are both keratinized and some non-keratinized [6].

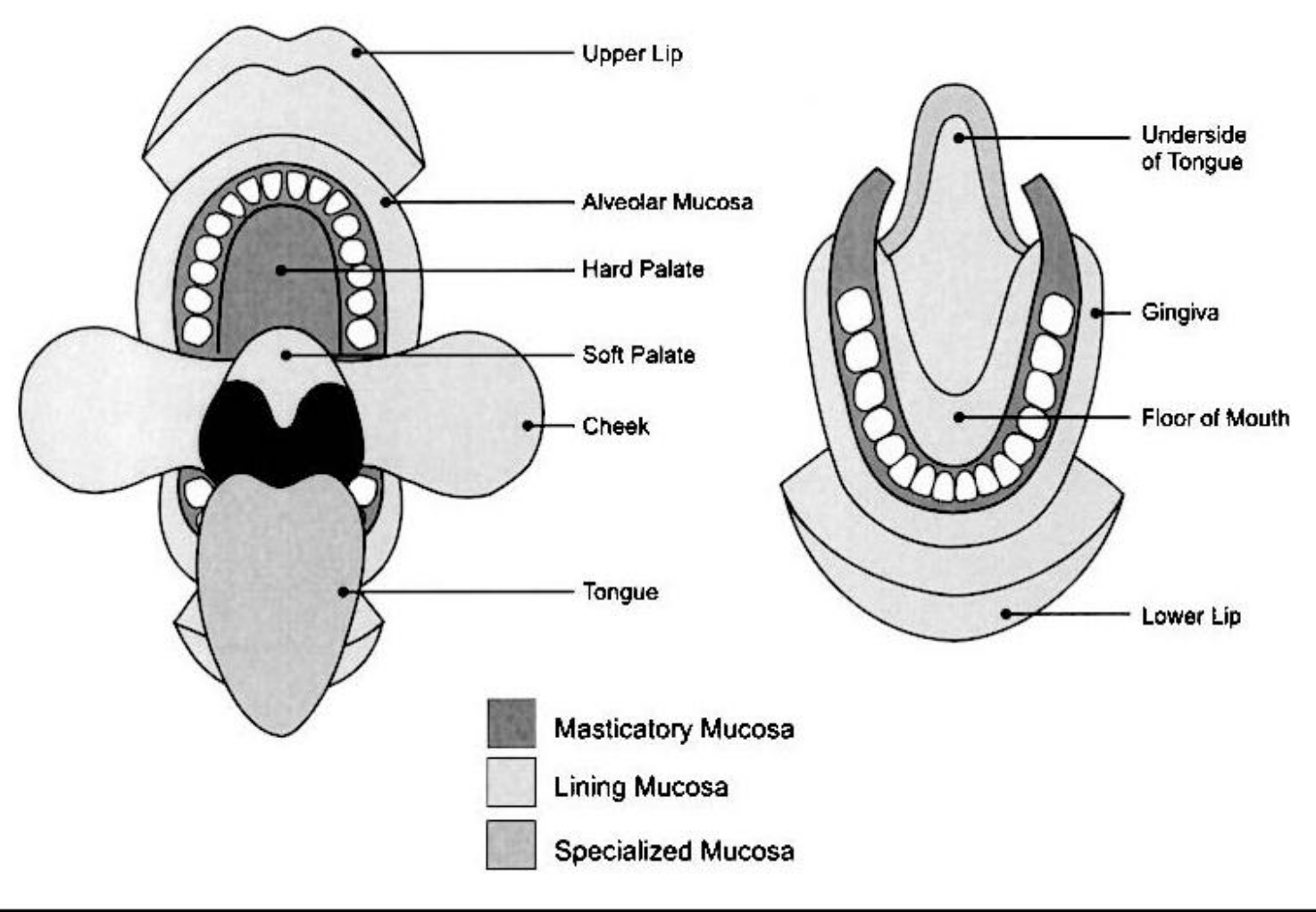

Figure 1: Schematic representation of the different linings of mucosa in mouth [7] 


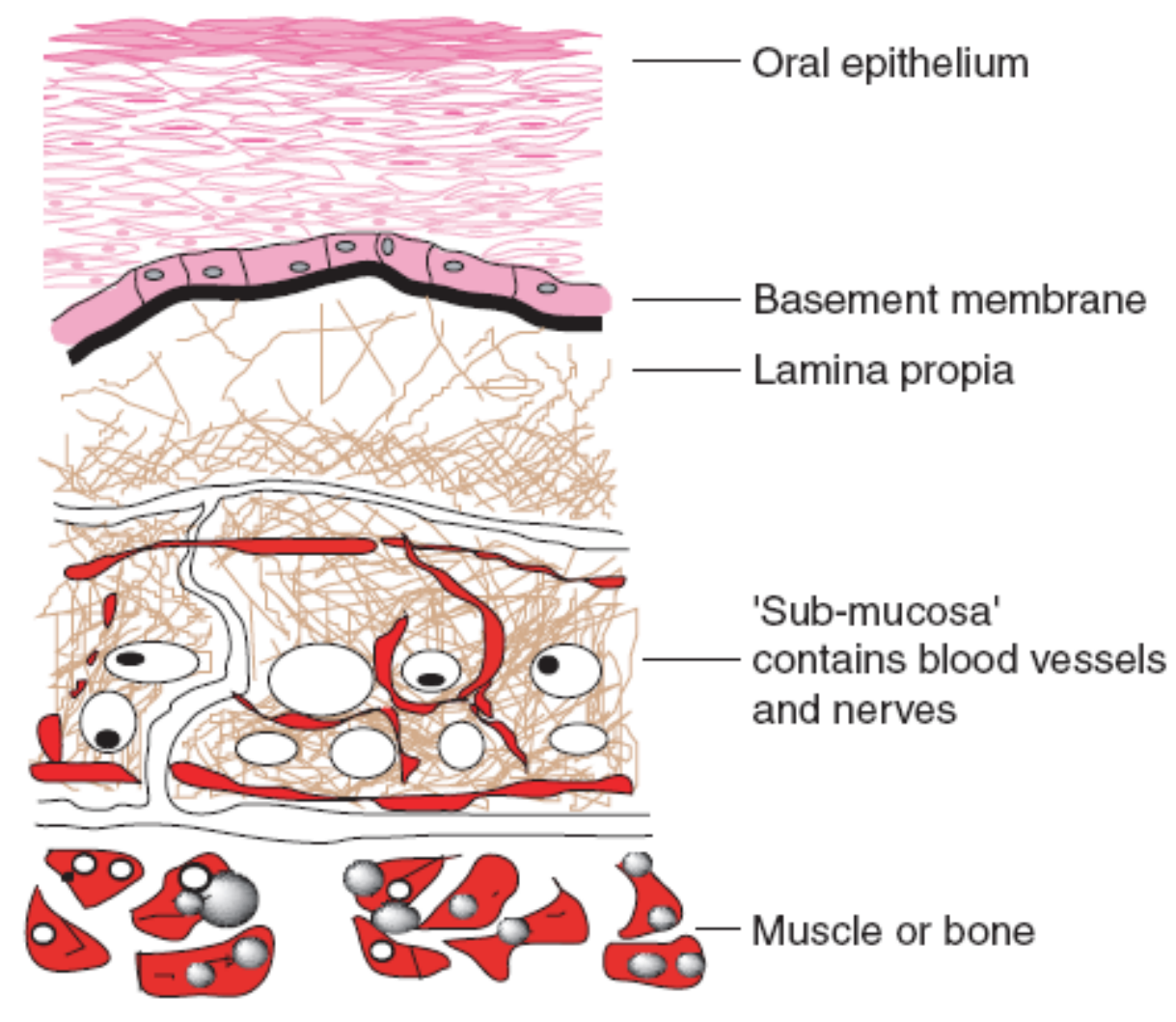

Figure 2: Schematic diagram of buccal mucosa [8]

\section{Physiological barriers for oral transmucosal drug delivery}

The environment of the oral cavity presents some significant challenges for systemic drug delivery. The drug needs to be released from the formulation to the delivery site (e.g. buccal or sublingual area) and pass through the mucosal layers to enter the systemic circulation. Certain physiological aspects of the oral cavity play significant roles in this process, including $\mathrm{pH}$, fluid volume, enzyme activity and the permeability of oral mucosa. For drug delivery systems designed for extended release in the oral cavity (e.g. mucodhesive systems), the structure and turnover of the mucosal surface is also a determinant of performance. Table 1 provides a comparison of the physiological characteristics of the buccal mucosa with the mucosa of the GI tract. 
Table 1: Comparison of different mucosa [9-12]

\begin{tabular}{|c|c|c|c|c|c|c|}
\hline $\begin{array}{c}\text { Absorptive } \\
\text { site }\end{array}$ & $\begin{array}{c}\text { Estimated } \\
\text { Surface area }\end{array}$ & $\begin{array}{c}\text { Percent } \\
\text { total } \\
\text { surface } \\
\text { area }\end{array}$ & $\begin{array}{c}\text { Local } \\
\mathrm{pH}\end{array}$ & $\begin{array}{c}\text { Mean } \\
\text { fluid } \\
\text { volume } \\
\text { (ml) }\end{array}$ & $\begin{array}{l}\text { Relative } \\
\text { enzyme } \\
\text { activity }\end{array}$ & $\begin{array}{c}\text { Relative } \\
\text { drug } \\
\text { absorption } \\
\text { capacity }\end{array}$ \\
\hline Buccal & $\begin{array}{l}100 \mathrm{~cm}^{2} \\
\left(0.01 \mathrm{~m}^{2}\right)\end{array}$ & 0.01 & $5.8-7.6$ & 0.9 & Moderate & High \\
\hline Stomach & $0.1-0.2 \mathrm{~m}^{2}$ & 0.20 & $1.0-3.0$ & 118 & High & High \\
\hline $\begin{array}{l}\text { Small } \\
\text { Intestine }\end{array}$ & $100 \mathrm{~m}^{2}$ & 98.76 & $3.0-4.0$ & 212 & High & High \\
\hline $\begin{array}{l}\text { Large } \\
\text { Intestine }\end{array}$ & $0.5-1.0 \mathrm{~m}^{2}$ & 0.99 & $4.0-6.0$ & 187 & Moderate & Low \\
\hline Rectum & $\begin{array}{c}200-400 \mathrm{~cm}^{2} \\
\left(0.04 \mathrm{~m}^{2}\right)\end{array}$ & 0.04 & $5.0-6.0$ & - & Low & Low \\
\hline
\end{tabular}

The principle physiological environment of the oral cavity, in terms of $\mathrm{pH}$, fluid volume and composition, is shaped by the secretion of saliva. Saliva is secreted by three major salivary glands (parotid, submaxillary and sublingual) and minor salivary or buccal glands situated in or immediately below the mucosa. The parotid and submaxillary glands produce watery secretion, whereas the sublingual glands produce mainly viscous saliva with limited enzymatic activity. The main functions of saliva are to lubricate the oral cavity, facilitate swallowing and to prevent demineralisation of the teeth. It also allows carbohydrate digestion and regulates oral microbial flora by maintaining the oral $\mathrm{pH}$ and enzyme activity [13, 14]. The daily total salivary volume is between 0.5 and $2.0 \mathrm{~L}$. However, the volume of saliva constantly available is around $1.1 \mathrm{ml}$, thus providing a relatively low fluid volume available for drug release from delivery systems compared to the GI tract. Compared to the GI fluid, saliva is relatively less viscous containing $1 \%$ organic and inorganic materials. In addition, saliva is a weak buffer with a $\mathrm{pH}$ around 5.5-7.0. Ultimately the $\mathrm{pH}$ and salivary compositions are dependant on the flow rate of saliva which in turn depends upon three factors: the time of day, the type of stimulus and the degree of stimulation [15]. For example, at high flow rates, the sodium and bicarbonate concentrations increase leading to an increase in the $\mathrm{pH}$. 
Saliva provides a water rich environment of the oral cavity which can be favourable for drug release from delivery systems especially those based on hydrophilic polymers. However, saliva flow decides the time span of the released drug at the delivery site. This flow can lead to premature swallowing of the drug before effective absorption occurs through the oral mucosa and is a well accepted concept as "saliva wash out". However, there is little research on to what extent this phenomenon affects the efficiency of oral transmucosal delivery from different drug delivery systems and thus further research needs to be conducted to better understand this effect.

Drug permeability through the oral (e.g. buccal/sublingual) mucosa represents another major physiological barrier for oral transmucosal drug delivery. The oral mucosal thickness varies depending on the site as does the composition of the epithelium. The characteristics of the different regions of interest in the oral cavity are shown in Table 2. The mucosa of areas subject to mechanical stress (the gingiva and hard palate) is keratinized similar to the epidermis. The mucosa of the soft palate, sublingual, and buccal regions, however, are not keratinized. The keratinized epithelia contain neutral lipids like ceramides and acylceramides which have been associated with the barrier function. These epithelia are relatively impermeable to water. In contrast, non-keratinized epithelia, such as the floor of the mouth and the buccal epithelia do not contain acylceramides and only have small amounts of ceramides [16]. They also contain small amounts of neutral but polar lipids, mainly cholesterol sulfate and glucosyl ceramides. These epithelia have been found to be considerably more permeable to water than keratinized epithelia $[17,18]$.

Table 2: Characteristics of oral mucosa

\begin{tabular}{|c|c|c|c|c|c|c|c|}
\hline $\begin{array}{c}\text { Tissue } \\
{[20]}\end{array}$ & Structure & $\begin{array}{l}\text { Thickness } \\
(\mu \mathrm{m})[20]\end{array}$ & $\begin{array}{c}\text { Turnover } \\
\text { time } \\
\text { (days) } \\
{[22]}\end{array}$ & $\begin{array}{c}\text { Surface } \\
\text { area }\left(\mathrm{cm}^{2}\right) \\
\pm \mathrm{SD}[6]\end{array}$ & $\begin{array}{c}\text { Permeability } \\
\text { [19] }\end{array}$ & $\begin{array}{l}\text { Residence } \\
\text { time [19] }\end{array}$ & $\begin{array}{c}\text { Blood } \\
\text { flow* } \\
{[21]}\end{array}$ \\
\hline Buccal & NK & $500-600$ & $5-7$ & $50.2 \pm 2.9$ & Intermediate & Intermediate & 20.3 \\
\hline Sublingual & NK & $100-200$ & 20 & $26.5 \pm 4.2$ & Very good & Poor & 12.2 \\
\hline Gingival & K & 200 & - & - & Poor & Intermediate & 19.5 \\
\hline Palatal & K & 250 & 24 & $20.1 \pm 1.9$ & Poor & Very good & 7.0 \\
\hline
\end{tabular}

NK is nonkeratinized tissue, $\mathrm{K}$ is Keratinized tissue and * In rhesus monkeys $(\mathrm{ml} / \mathrm{min} / 100 \mathrm{~g}$ tissue). 
Within the oral mucosa, the main penetration barrier exists in the outermost quarter to one third of the epithelium [23, 24]. The relative impermeability of the oral mucosa is predominantly due to intercellular materials derived from the so-called membrane coating granules Q (MCGs) [2]. MCGs are spherical or oval organelles that are $100-300 \mathrm{~nm}$ in diameter and found in both keratinized and non-keratinized epithelia [25]. They are found near the upper, distal, or superficial border of the cells, although a few occur near the opposite border [25]. Several hypotheses have been suggested to describe the functions of MCGs, including membrane thickening, cell adhesion, production of a cell surface coat, cell desquamation and as a permeability barrier. Hayward [25] summarised that the MCGs discharge their contents into the intercellular space to ensure epithelial cohesion in the superficial layers, and this discharge forms a barrier to the permeability of various compounds. Cultured oral epithelium devoid of MCGs has been shown to be permeable to compounds that do not typically penetrate the oral epithelium [26]. In addition, permeation studies conducted using tracers of different sizes have demonstrated that these tracer molecules did not penetrate any further than the top 1-3 cell layers. When the same tracer molecules were introduced sub-epithelially, they penetrated through the intercellular spaces. This limit of penetration coincides with the level where MCGs are observed. This same pattern is observed in both keratinized and non-keratinized epithelia [3], which indicates that MCGs play a more significant role as a barrier to permeation compared to the keratinisation of the epithelia [27].

The cells of the oral epithelia are surrounded by an intercellular ground substance called mucus, the principle components of which are complexes made up of proteins and carbohydrates; its thickness ranging from 40 to $300 \mu \mathrm{m}$ [28]. In the oral mucosa; mucus is secreted by the major and minor salivary glands as part of saliva. Although most of the mucus is water $(\approx 95-99 \%$ by weight) the key macromolecular components are a class of glycoprotein known as mucins (1-5\%). Mucins are large molecules with molecular masses ranging from 0.5 to over $20 \mathrm{MDa}$ and contain large amounts of carbohydrate. Mucins are made up of basic units $(\approx 400-500 \mathrm{kDa})$ linked together into linear arrays. These big molecules are able to join together to form extended three-dimensional network [29] which acts as a lubricant allowing cells to move relative to one another, and may also contribute to cell-cell adhesion [14]. At physiological $\mathrm{pH}$, the mucus network carries a negative charge due to the sialic acid and sulfate residues and forms a strongly cohesive gels structure that will bind to the epithelial cell surface as a gelatinous layer [30-32]. This gel layer is believed to 
play a role in mucoadhesion for drug delivery systems which work on the principle of adhesion to the mucosal membrane and thus extend the dosage form retention time at the delivery site.

Another factor of the buccal epithelium that can affect mucoadhesion of drug delivery systems is the turnover time. The turnover time for the buccal epithelium has been estimated 3-8 days compared to about 30 days for the skin [2] which may change permeability characteristics frequently.

\section{Physiological opportunities for oral transmucosal drug delivery}

Despite the physiological challenges, the oral mucosa, due its unique structural and physiological properties, offers several opportunities for systemic drug delivery. As the mucosa is highly vascularized any drug diffusing across the oral mucosa membranes has direct access to the systemic circulation via capillaries and venous drainage and will bypass hepatic metabolism. The rate of blood flow through the oral mucosa is substantial, and is generally not considered to be the rate-limiting factor in the absorption of drugs by this route (Table 2).

For oral delivery through the GI tract, the drug undergoes a rather hostile environment before absorption. This includes a drastic change in GI pH (from $\mathrm{pH} 1-2$ in the stomach to 7-7.4 in the distal intestine), unpredictable GI transit, the presence of numerous digestive enzymes and intestinal flora $[33,34]$. In contrast to this harsh environment of the GI tract, the oral cavity offers relatively consistent and friendly physiological conditions for drug delivery which are maintained by the continual secretion of saliva. Compared to secretions of the GI tract, saliva is a relatively mobile fluid with less mucin, limited enzymatic activity and virtually no proteases [35].

Enzyme degradation in the GI tract is a major concern for oral drug delivery. In comparison, the buccal and sublingual regions have less enzymes and lower enzyme activity, which is especially favourable to protein and peptide delivery. The enzymes that are present in buccal mucosa are believed to include aminopeptidases, carboxypeptidases, dehydrogenases and esterases. Aminopeptidases may represent a major metabolic barrier to the buccal delivery of peptide drugs. Proteolytic activity has been identified in buccal tissue homogenates from various species and a number of peptides have been shown to undergo degradation [36]. Bernkop-Schnurch and co-workers [37] studied the peptidase activity on the surface of porcine buccal mucosa and found that no carboxypeptidase or dipeptidyl peptidase IV 
activity was detected on the buccal mucosa, while aminopeptidase $\mathrm{N}$ activity was detected using Leu-p-nitroanilide. However, this study represents only the surface of procine mucosa and hence more research will be required to fully characterize the levels and type of different enzymes presents especially in human buccal mucosa.

The buccal and sublingual routes are the focus for drug delivery via the oral mucosa because of the higher overall permeability compared to the other mucosa of the mouth. The effective permeability coefficient values reported in the literature across the buccal mucosa for different molecules, range from a lower limit of $2.2 \times 10^{9} \mathrm{~cm} / \mathrm{s}$ for dextran 4000 across rabbit buccal membrane to an upper limit of $1.5 \times 10^{5} \mathrm{~cm} / \mathrm{s}$ for both benzylamine and amphetamine across rabbit and dog buccal mucosa, respectively [2]. The oral mucosa is believed to be 44000 times more permeable than that of skin [24]. Squier and co-workers [38] revealed that the permeability of water through the buccal mucosa was approximately 10 times higher, whilst in floor of the mouth the permeability was approximately 20 times higher than skin (Table 3). In another study by Squier and Hall [39], the permeability constant was calculated for water and Horseradish peroxidase across skin and oral mucosal surface (Table 4).

Table 3: Permeabilities of water for human skin and oral mucosa regions (Adapted from Squier and co-workers [38])

\begin{tabular}{lc}
\hline \multicolumn{1}{c}{ Region $^{\mathrm{a}}$} & $K p\left(\times 10^{-7} \pm \mathrm{SEM} \mathrm{cm} / \mathrm{min}\right)$ \\
\hline Skin & $44 \pm 4^{\mathrm{b}}$ \\
\hline Oral mucosa & $470 \pm 27$ \\
\hline Hard palate & $579 \pm 16$ \\
Buccal mucosa & $772 \pm 23$ \\
Lateral border of tongue & $973 \pm 33$ \\
Floor of mouth & \\
\hline
\end{tabular}

a. Human $(\mathrm{n}=58)$.

b. Permeability constant significant compared to oral mucosa at $\mathrm{P}<0.05$. 
Table 4: Regional difference in permeability expressed in terms of a uniform permeability barrier (Adapted from Squier and Hall [39])

\begin{tabular}{|c|c|c|c|c|}
\hline \multirow[t]{2}{*}{ Tissue region } & \multicolumn{2}{|c|}{ Thickness $(\mu \mathrm{m} \pm$ SEM $)$} & \multicolumn{2}{|c|}{$\begin{array}{l}\text { Mean Kp expressed in terms of a } \\
\text { uniform barrier of } 100 \mu \mathrm{m} \text { thick } \\
\left.\qquad \pm \mathrm{SEM} \times 10^{-7}\right)\end{array}$} \\
\hline & $\begin{array}{c}\text { Total } \\
\text { epithelium }\end{array}$ & $\begin{array}{l}\text { Permeability } \\
\text { barrier }\end{array}$ & Water & $\begin{array}{c}\text { Horseradish } \\
\text { peroxidise }\end{array}$ \\
\hline Skin & $69 \pm 4$ & $16 \pm 1$ & $21.1 \pm 4.3$ & $9.4 \pm 1.8$ \\
\hline Gingiva & $208 \pm 9$ & $35 \pm 4$ & $98.3 \pm 16.0$ & $79.5 \pm 11.4$ \\
\hline Buccal mucosa & $772 \pm 20$ & $282 \pm 17$ & $173.2 \pm 24.6$ & $99.1 \pm 10.6$ \\
\hline Floor of mouth & $192 \pm 7$ & $23 \pm 1$ & $1271.3 \pm 203.1$ & $331.6 \pm 51.9$ \\
\hline
\end{tabular}

Drug can be transported across epithelial membranes by passive diffusion, carrier-mediated, active transport or other specialized mechanisms. Most studies of buccal absorption indicate that the predominant mechanism is passive diffusion across lipid membranes via either the paracellular or transcellular pathways (Figure 3) [40-44]; although these may actually be the same pathway. The hydrophilic nature of the paracellular spaces and cytoplasm provides a permeability barrier to lipophilic drugs but can be favourable for hydrophilic drugs. In contrast, the transcellular pathway involves drugs penetrating through one cell and the next until entering the systemic circulation. The lipophilic cell membrane offers a preferable route for lipophilic drugs compared to hydrophilic compounds [1]. Drugs can transverse both pathways simultaneously although one route could be predominant depending on the physicochemical properties of the drug [31].

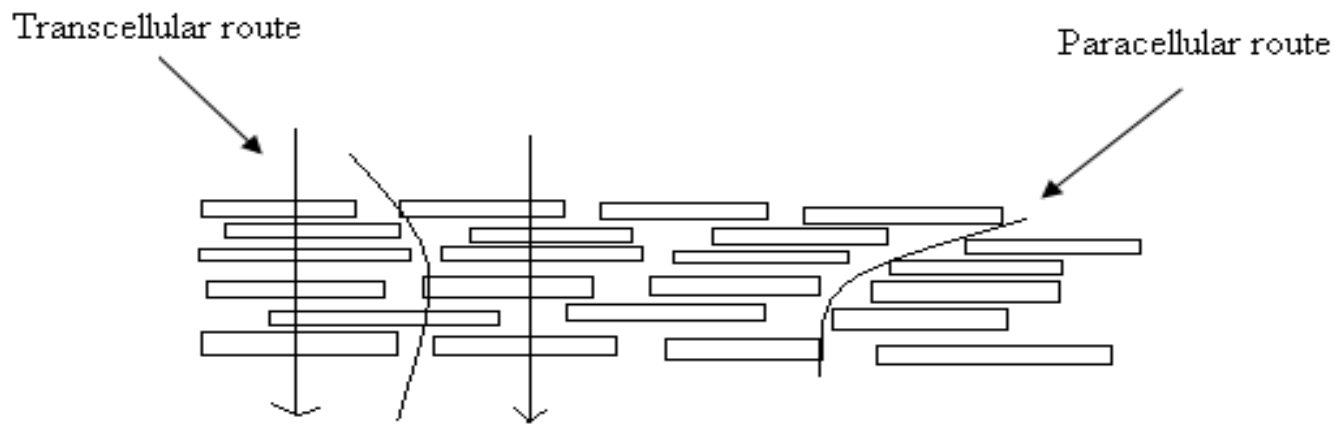

Figure 3: Schematic representation of different route of drug permeation 
Although passive diffusion is the predominant mechanism of absorption from the oral mucosa, specialized transport mechanisms have also been reported for a few drugs and nutrients. Study by Kurosaki and co-workers [45] reported that the rate of absorption of Dglucose from the dorsal and ventral surface of the tongue was significantly greater than that of L-glucose, which indicated the occurrence of some specialized transport mechanism. In addition, the existence of sodium-dependant D-glucose transport system was reported across stratified cell layer of human oral mucosal cells [46]. Table 5 provides examples of several drugs transported via different mechanisms across the buccal mucosa.

Table 5: Examples of drug transported via different mechanisms through buccal mucosa.

\begin{tabular}{|c|c|c|c|c|}
\hline Name of Drug & Transport mechanism & Path way & Tissue & References \\
\hline $\begin{array}{l}\text { 5-Aza-2'- } \\
\text { deoxycytidine }\end{array}$ & Passive & Not defined & Buccal mucosa & 40 \\
\hline $\begin{array}{l}\text { 2', 3'- } \\
\text { dideoxycytidine }\end{array}$ & Passive & Not defined & Buccal mucosa & 41 \\
\hline Flecainide & Passive & Paracellular & Buccal mucosa & 42 \\
\hline Sotalol & Passive & Paracellular & Buccal mucosa & 42 \\
\hline Nicotine & Passive & $\begin{array}{l}\text { Paracellular, } \\
\text { Transcellular }\end{array}$ & $\begin{array}{l}\text { TR146 Cell culture } \\
\text { and buccal }\end{array}$ & 43 \\
\hline Lamotrigine & Passive & Transcellular & Buccal & 44 \\
\hline Galantamine & Passive & Not defined & $\begin{array}{l}\text { Human oral } \\
\text { epithelium and } \\
\text { buccal mucosa }\end{array}$ & 47 \\
\hline Naltrexone & Passive & Not defined & Buccal mucosa & 48 \\
\hline Buspirone & Passive & Transcellular & Buccal mucosa & 49 \\
\hline Ondansatron $\mathrm{HCl}$ & Passive & Not defined & Buccal mucosa & 50 \\
\hline $\begin{array}{l}\text { Monocarboxylic } \\
\text { acids }\end{array}$ & Carrier mediated & $\begin{array}{l}\text { Carrier } \\
\text { mediated }\end{array}$ & $\begin{array}{l}\text { Primary cultured } \\
\text { epithelial cells }\end{array}$ & 51,52 \\
\hline Glucose & Carrier mediated & $\begin{array}{l}\text { Carrier } \\
\text { mediated }\end{array}$ & $\begin{array}{l}\text { Buccal, oral } \\
\text { mucosal cells and } \\
\text { dorsum of tongue }\end{array}$ & 53 \\
\hline
\end{tabular}




\section{Oral transmucosal drug delivery technologies}

Continuous research into the improvement of the oral transmucosal delivery of drugs has resulted in the development of several conventional and novel dosage forms like solutions, tablets/lozenges, chewing gums, sprays, patches and films, hydrogels, hollow fibres and microspheres. These dosage forms can be broadly classified into liquid, semi-solid, solid or spray formulations [54]. Oral transmucosal systems for systemic drug delivery are usually designed to deliver the drug for either i) rapid drug release for immediate and quick action, ii) pulsatile release with rapid appearance of drug into systemic circulation and subsequent maintenance of drug concentration within therapeutic profile or iii) controlled release for extended period of time (as depicted in Figure 4).

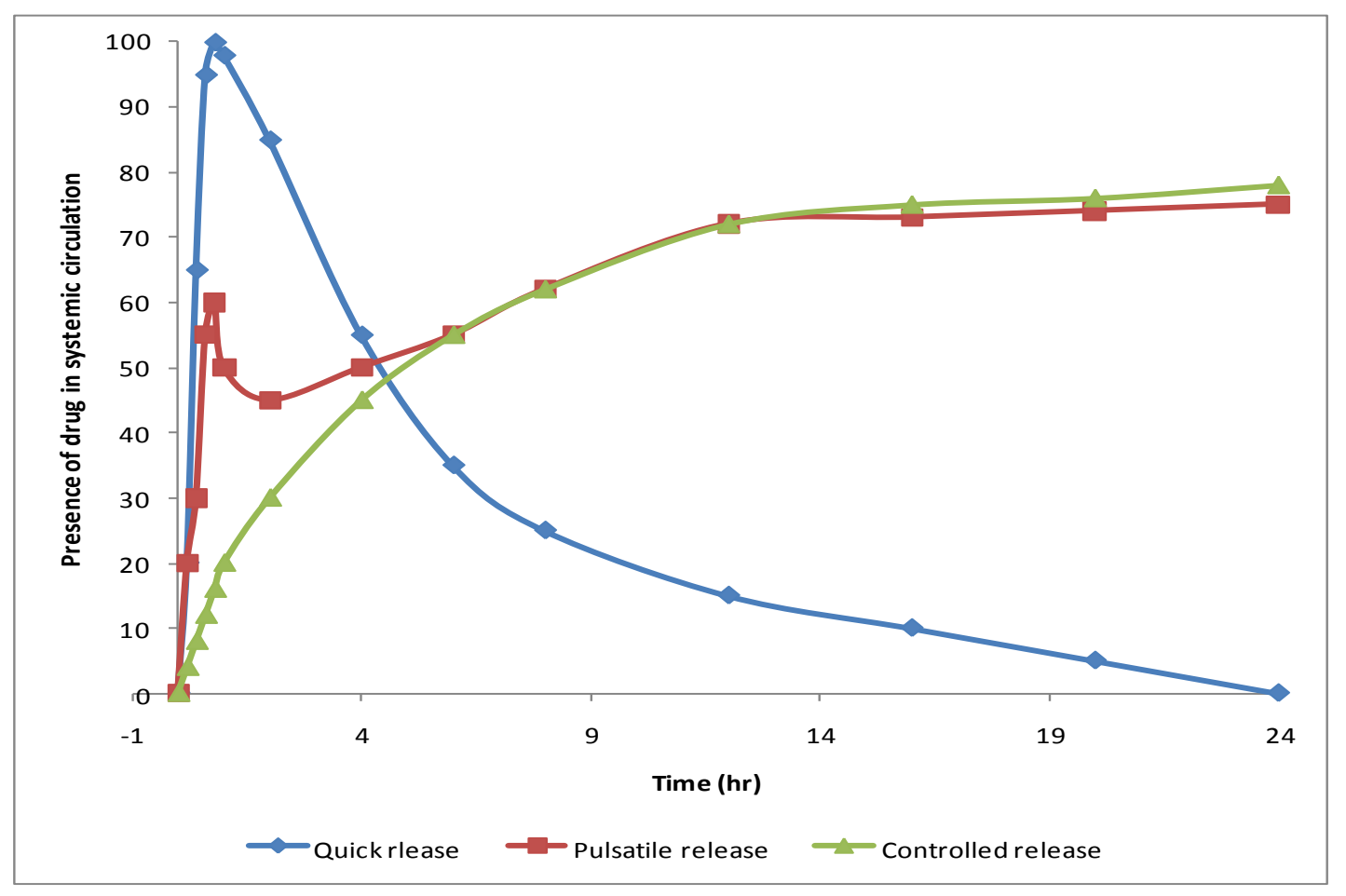

Figure 4: Schematic representation of different type of mucosal drug delivery system

Several companies are currently engaged in development and commercialization of drug delivery technologies based on oral transmucosal systems. Table 6 shows the list of products commercially approved for oral transmucosal administration. The list of companies currently engaged in developing technology platforms for oral transmucosal drug delivery system is shown in Table 7. The majority of the commercially available formulations are solid dosage forms such as tablets and lozenges. A few companies have had successes in developing technology platforms for films or patches with most aimed at achieving rapid drug release 
and clinical response. The limitations associated with such type of dosage forms include uncontrolled swallowing of released drug into GI tract and difficulties in holding the dosage form at the site of absorption. These are the areas where more research focus is required, especially using mucoadhesive systems.

Table 6: Commercially available oral transmucosal drug delivery systems [35]

\begin{tabular}{|c|c|c|c|c|}
\hline Drug & $\begin{array}{c}\text { Dosage } \\
\text { form }\end{array}$ & $\begin{array}{l}\text { Type of } \\
\text { release }\end{array}$ & Product Name & Manufacturer \\
\hline \multirow[t]{3}{*}{ Fentanyl citrate } & Lozenge & Quick & Actiq & Cephalon \\
\hline & Tablet & Quick & Fentora & Cephalon \\
\hline & Film & Quick & Onsolis & Meda Pharmaceutical Inc. \\
\hline Buprenorphine & Tablet & Quick & Subutex & Reckitt Benckiser \\
\hline \multicolumn{5}{|l|}{$\mathrm{HCl}$} \\
\hline Buprenorphine & Tablet & Quick & Suboxane & Reckitt Benckiser \\
\hline \multicolumn{5}{|l|}{$\mathrm{HCl}$ and } \\
\hline \multicolumn{5}{|l|}{ naloxone } \\
\hline \multicolumn{5}{|l|}{$\mathrm{HCl}$} \\
\hline Proclorperazine & Tablet & Controlled & Buccastem & Reckitt Benckiser \\
\hline Testosterone & Tablet & Controlled & Striant SR & Columbia Pharmaceuticals \\
\hline \multirow[t]{2}{*}{ Nitroglycerine } & Tablet, & Quick & Nitrostat & W Lambert-P Davis-Pfizer \\
\hline & Spray & & & Pharmaceuticals \\
\hline Glyceryl trinitrate & Spray & Quick & Nitromist & NovaDel \\
\hline \multirow[t]{2}{*}{ Zolpidem } & Spray & Quick & Zolpimist & NovaDel \\
\hline & Tablet & Quick & Suscard & Forest Laboratories \\
\hline \multirow[t]{2}{*}{ Nicotine } & $\begin{array}{l}\text { Chewing } \\
\text { gum }\end{array}$ & Quick & Nicorette & GSK Consumer Health \\
\hline & Lozenge & Quick & Nicotinelle & Novartis Consumer Health \\
\hline Miconazole & Tablet & Quick & Loramyc & BioAlliance Pharma SA \\
\hline Cannabis-derived & Spray & Quick & Sativex & GW Pharmaceuticals, PLC \\
\hline Insulin & Spray & Quick & Oral-lyn & Generex Biotechnology \\
\hline
\end{tabular}


Table 7: List of companies with their technology platforms based on oral transmucosal system

\begin{tabular}{|c|c|c|}
\hline Company & Technology & References \\
\hline IntelGenx & $\begin{array}{l}\text { VersaFilm (Quick release wafer } \\
\text { technology) }\end{array}$ & 55 \\
\hline Bioenvelop & Thinsol (edible film technology) & 56 \\
\hline HealthSport and InnoZen & Bilayer film-strip & 57 \\
\hline BioFilm & Dissolvable thin film & 58 \\
\hline Meldex & $\begin{array}{l}\text { XGel (Films), SoluLeaves (Films), } \\
\text { WaferTab (Film strip), OraDisc } \\
\text { (disc) }\end{array}$ & 59 \\
\hline Uluru Inc & OraDisc (disc) & $60-62$ \\
\hline MonoSol Rx & MonoSol Rx thin film & 63 \\
\hline Passion for Life Healthcare & Snoreeze Oral strips & 64,65 \\
\hline GW Pharma & Sativex Buccal Spray & 66 \\
\hline \multirow[t]{2}{*}{ Generex Biotechnology } & Oral spray (RapidMist) technology & 67 \\
\hline & MetControl chewing gum & 67 \\
\hline NovaDel & Novamist spray technology & 68 \\
\hline $\begin{array}{l}\text { Biodelivery Sciences } \\
\text { International (BDSI) }\end{array}$ & BEMA technology & 69,70 \\
\hline Transcept Pharmaceutical Inc. & Sublingual tablets & 71 \\
\hline Labtec Pharma & RapidFilm technology & $72-75$ \\
\hline MedPharm Ltd & $\begin{array}{l}\text { MedRo mucoadhesive spray } \\
\text { technology }\end{array}$ & 76 \\
\hline
\end{tabular}

\subsection{Mucoadhesive systems}

Other than the low surface area available for drug absorption in the buccal cavity, the retention of the dosage form at the site of absorption is another factor which determines the success or failure of buccal drug delivery system. The utilization of mucoadhesive systems is essential to maintain an intimate and prolonged contact of the formulation with the oral mucosa allowing a longer duration for absorption. Some adhesive systems deliver the drug towards the mucosa only with an impermeable product surface exposed to the oral cavity which prevents the drug release into oral cavity [77]. For example, Lopez and co-workers 
[78] designed bilaminated films to provide unidirectional release of drug and avoid buccal leakage. They contained a bioadhesive layer made up of chitosan, polycarbophil, sodium alginate and gellan gum while backing layer made up of ethyl cellulose.

\subsubsection{Theories of mucoadhesion}

The most widely investigated group of mucoadhesives used in buccal drug delivery systems are hydrophilic macromolecules containing numerous hydrogen bond-forming groups [79]. The presence of hydroxyl, carboxyl or amine groups on the molecules favours adhesion. They are called 'wet' adhesives as they are activated by moistening and will adhere nonspecifically to many surfaces. Unless water uptake is restricted, they may over hydrate to form slippery mucilage. For dry or partially hydrated dosage forms two basic steps in mucoadhesion have been identified [80]. Step one is the 'contact stage' where intimate contact is formed between the mucoadhesive and mucous membrane. Within the buccal cavity the formulation can usually be readily placed into contact with the required mucosa and held in place to allow adhesion to occur. Step two is the 'consolidation' stage where various physicochemical interactions occur to consolidate and strengthen the adhesive joint, leading to prolonged adhesion.

Mucoadhesion is a complex process and numerous theories have been presented to explain the mechanisms involved. These theories include mechanical-interlocking, electrostatic, diffusion- interpenetration, adsorption and fracture processes [81], whilst undoubtedly the most widely accepted theories are founded upon surface energy thermodynamics and interpenetration/diffusion [82]. The wettability theory is mainly applicable to liquid or low viscosity mucoadhesive systems and is essentially a measure of the spreadability of the drug delivery system across the biological substrate [83]. The electronic theory describes adhesion occurs by means of electron transfer between the mucus and the mucoadhesive system arising through differences in their electronic structures. The electron transfer between the mucus and the mucoadhesive results in the formation of a double layer of electrical charges at the mucus and mucoadhesive interface. The net result of such a process is the formation of attractive forces within this double layer [84]. According to fracture theory, the adhesive bond between systems is related to the force required to separate both surfaces from one another. This "fracture theory" relates the force for polymer detachment from the mucus to the strength of their adhesive bond. The work of fracture has been found to be greater when the polymer network strands are longer or if the degree of cross-linking within such as system is reduced [85]. According to adhesion theory, adhesion is defined as being the result of 
various surface interactions (primary and secondary bonding) between the adhesive polymer and mucus substrate. Primary bonds due to chemisorption result in adhesion due to ionic, covalent and metallic bonding, which is generally undesirable due to their permanency [86]. The diffusion-interlocking theory proposes the time-dependent diffusion of mucoadhesive polymer chains into the glycoprotein chain network of the mucus layer. This is a two-way diffusion process with penetration rate being dependent upon the diffusion coefficients of both interacting polymers [87].

\subsubsection{Polymers for mucoadhesive systems}

The polymeric attributes that are pertinent to high levels of retention at applied and targeted sites via mucoadhesive bonds include hydrophilicity, negative charge potential and the presence of hydrogen bond forming groups. Additionally, the surface free energy of the polymer should be adequate so that 'wetting' with the mucosal surface can be achieved. The polymer should also possess sufficient flexibility to penetrate the mucus network, be biocompatible, non-toxic and economically favourable [88]. According to the literature mucoadhesive polymers are divided into first generation mucoadhesive polymers and second generation novel mucoadhesive polymers. The first generation polymers are divided into three major groups according to their surface charges which include anionic, cationic and non-ionic polymers. The anionic and cationic polymers exhibit stronger mucoadhesion [89].

Anionic polymers are the most widely employed mucoadhesive polymers within pharmaceutical formulations due to their high mucoadhesive functionality and low toxicity. Such polymers are characterised by the presence of carboxyl and sulphate functional groups that give rise to a net overall negative charge at $\mathrm{pH}$ values exceeding the $\mathrm{pKa}$ of the polymer. Typical examples include polyacrylic acid (PAA) and its weakly cross-linked derivatives and sodium carboxymethyl cellulose (Na CMC). PAA and $\mathrm{Na}$ CMC possess excellent mucoadhesive characteristics due to the formation of strong hydrogen bonding interactions with mucin [90]. Among the cationic polymer systems, undoubtedly chitosan is the most extensively investigated within the current scientific literature [91]. Chitosan is a cationic polysaccharide, produced by the deacetylation of chitin, the most abundant polysaccharide in the world, next to cellulose [91]. Chitosan is a popular polymer to use due to its biocompatibility, biodegradability and favourable toxicological properties [92]. Chitosan has been reported to bind via ionic interactions between primary amino functional groups and the sialic acid and sulphonic acid substructures of mucus [93]. The major benefit of using chitosan within pharmaceutical applications has been the ease with which various chemical 
groups may be added, in particular to the C-2 position allowing for the formation of novel polymers with added functionality. Using such modifications, the properties of chitosan may be tailored to suit the requirements of specific pharmaceutical-technological challenges [94] although this often results in additional regulatory requirements as it becomes a new excipient with all the added problems of qualifying from a safety basis.

Unlike first-generation non-specific platforms, certain second-generation polymer platforms are less susceptible to mucus turnover rates, with some species binding directly to mucosal surfaces; more accurately termed 'cytoadhesives'. Furthermore as surface carbohydrate and protein composition at potential target sites vary regionally, more accurate drug delivery may be achievable [81]. Lectins are naturally occurring proteins that play a fundamental role in biological recognition phenomena involving cells and proteins. After initial mucosal cellbinding, lectins can either remain on the cell surface or in the case of receptor-mediated adhesion possibly become internalised via endocytosis [95]. Although lectins offer significant advantages in relation to site targeting, many are toxic or immunogenic, and the effects of repeated lectin exposure are largely unknown. It is also feasible that lectin-induced antibodies could block subsequent adhesive interactions between mucosal epithelial cell surfaces and lectin delivery vehicles. Moreover, such antibodies may also render individuals susceptible to systemic anaphylaxis on subsequent exposure [95].

Thiolated polymers (thiomers) are a type of second-generation mucoadhesive derived from hydrophilic polymers such as polyacrylates, chitosan or deacetylated gellan gum [96]. The presence of thiol groups allows the formation of covalent bonds with cysteine rich sub domains of the mucus gel layer leading to increased residence time and improved bioavailability [97]. Whilst first-generation mucoadhesive platforms are facilitated via noncovalent secondary interactions, the covalent bonding mechanisms involved in secondgeneration systems lead to interactions that are less susceptible to changes in ionic strength and/or the $\mathrm{pH}[98]$.

\section{2 Dosage forms}

\subsubsection{Liquid dosage forms}

Liquid dosage forms include solutions or suspensions made of drug solubilised or suspended into suitable aqueous vehicles. Such types of dosage forms are usually employed to exert local action into the oral cavity and several antibacterial mouthwashes and mouth-freshener are commercially available for this purpose. The limitation associated with these liquid 
dosage forms are that they are not readily retained or targeted to buccal mucosa and can deliver relatively uncontrolled amounts of drug throughout oral cavity. Patel and co-workers [99] found that polymers be adsorbed from solution onto buccal cells in vivo. From the wide range of polymer solutions screened, chitosan gave the greatest binding, followed by methylcellulose, gelatin, carbopol and polycarbophil.

Drug present in the liquid dosage forms can also been delivered in a more controlled manner through the use of iontophoresis techniques, which are well known for the delivery of drugs through skin, but have also been investigated for drug delivery across the buccal mucosa. Jacobsen [100] studied the iontophoretic drug delivery of atenolol hydrochloride solution employing three-chamber permeation cell in vitro. The delivery across porcine buccal mucosa increased proportionally to increased initial donor concentration, increased "on time" of current on/ off ratio and increased current density. Microscopical evaluation of hematoxyilin-eosin stained sections of porcine buccal mucosa showed only minute morphological alterations after conducting $8 \mathrm{~h}$ passive permeation whilst $8 \mathrm{~h}$ iontophoretic treatment showed disordering of the outer epithelial cell layers; the alterations being more pronounced in mucosa from reference chambers than donor chambers. Campisi and coworkers [101] reported that the iontophoretic buccal drug delivery of naltrexone was a promising development as naltrexone appeared in the plasma of pigs within 5-10 min of administration and reached to peak around $90 \mathrm{~min}$. After $6 \mathrm{~h}$, the plasma level of naltrexone delivered via iontophoresis was higher compared to that of naltrexone delivered intravenously. Such findings were explained by the presence of a drug reservoir within the buccal mucosa after iontophoresis from which naltrexone released gradually and was systemically available.

\subsubsection{Semisolid dosage forms}

Semisolid dosage forms usually include gels, creams and ointments, which are applied topically into the mucosal surface for either local or systemic effects. These typically contain a polymer and drug plus any required excipient dissolved or suspended as a fine powder in an aqueous or non-aqueous base. Hydrogels can also be used in semi-solids for drug delivery to the oral cavity. These are formed from polymers and can be hydrated in an aqueous environment without dissolution, acting as drug delivery systems by physically entrapping molecules, which are then slowly released by diffusion or erosion after gel hydration [102]. Semi-solid formulations can be applied using the finger (or syringe) to a target region and tend to be more acceptable in terms of mouth feel to patients relative to a solid dosage form. 
However, they may deliver variable amounts of active ingredients in comparison with a unit dosage form [7]. Hydrogels are formed from polymers and may be hydrated in an aqueous environment without dissolution, acting as drug delivery systems by physically entrapping molecules, which are then slowly released by diffusion or erosion after gel hydration [102]. Semisolid systems have the advantage of being deliverable with a syringe, with a consequent ease of placement to the periodontal pockets [103] and easy dispersion throughout the mucosa of the oral cavity. However, they may deliver variable amounts of active ingredients in comparison with a unit dosage form [7]. Another drawback of semi-solid dosage forms designed for use in the oral cavity is the poor retention at the site of application especially when the hydrogel polymer has no adhesive properties. This drawback can be minimized or eliminated by the incorporation of a bioadhesive polymer into the formulation [104]. A mucoadhesive gel of risperidone containing Poloxamer 407 and Carbopol 974 was able to achieve a steady state flux of $64.85 \pm 8.0 \mu \mathrm{g} / \mathrm{cm}^{2} / \mathrm{h}$ in an in vitro permeation study, which was extrapolated to an in vivo plasma concentration of 11.2-56.1 $\mu \mathrm{g} / \mathrm{L}$ for mucosal application area between 2 and $10 \mathrm{~cm}^{2}$. As such and assuming that these predicted plasma concentrations are within the therapeutic range of risperidone required in humans, delivery of risperidone via the buccal mucosa has potential for treatment of schizophrenia [105]. In addition, Perioli and co-workers [106] proposed emulgels (gellified emulsion) made up of Pemulin $^{\circledR} 1621$ as polymeric emulsifier and Compritol $^{\circledR} 888$ ATO as an internal oily phase for the buccal delivery of flurbiprofen and found that the drug release was controlled with 50$80 \%$ of drug release within 100 min of application. In addition, the emulgels were reported to be retained on human buccal mucosa for an average period of one hour.

\subsubsection{Solid dosage forms}

\subsubsection{Tablets/Lozenges}

These are solid dosage forms prepared by the compression of powder mixes that can be placed into contact with the oral mucosa and allowed to dissolve or adhere depending on the type of excipients incorporated into the dosage form. They can deliver drug multidirectionally into the oral cavity or to the mucosal surface. Alternatively, the dosage form can contain a impermeable backing layer to ensure that drug is delivered unidirectionally. Disadvantages of buccal tablets can include patient acceptability (mouth feel, taste and irritation) and the nonubiquitous distribution of drug within saliva for local therapy [7]. It is important to point out the possible problems that children and the elderly may experience with the use of adhesive tablets which include the possible discomfort 
provoked by the material applied to the mucosa and the possibility of the dosage form separating from the mucosa, being swallowed, and then adhering to the wall of the esophagus. A typical bioadhesive formulation of this type consists of a bioadhesive polymer (such as polyacrylic acids or a cellulose derivative), alone or in combination, incorporated into a matrix containing the active agent and excipients, and perhaps a second impermeable layer to allow unidirectional drug delivery $[107,108]$.

(a)

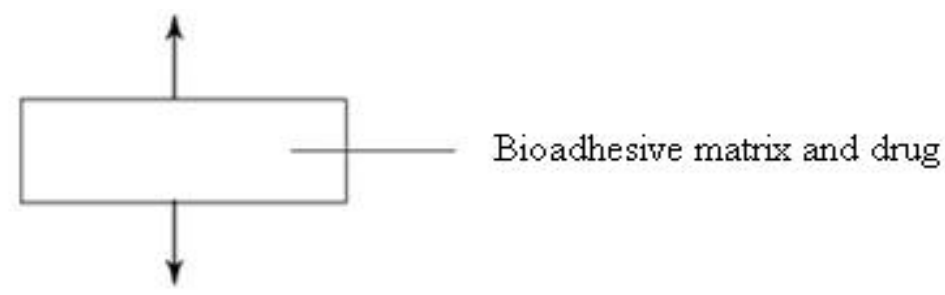

(b)

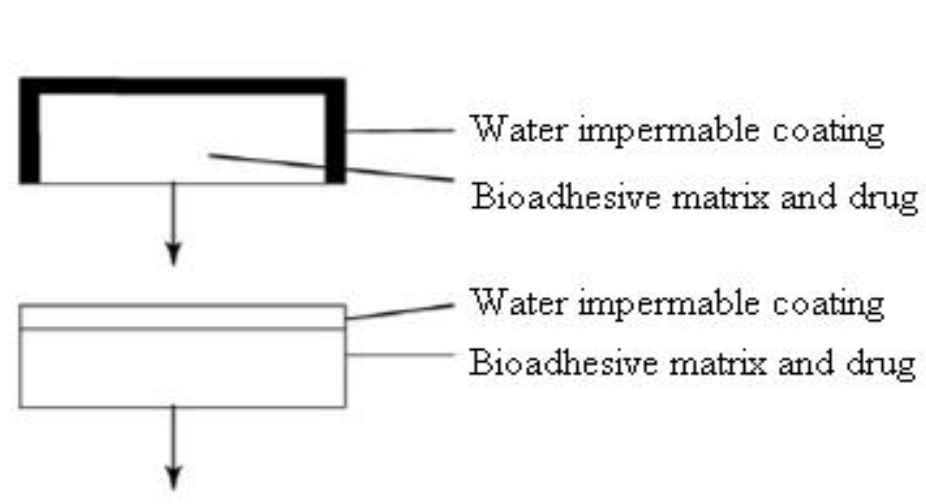

(c)

(d)

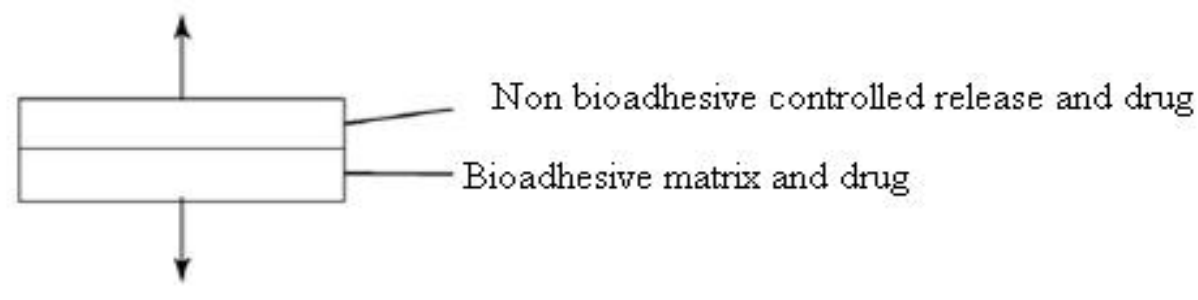

(e)

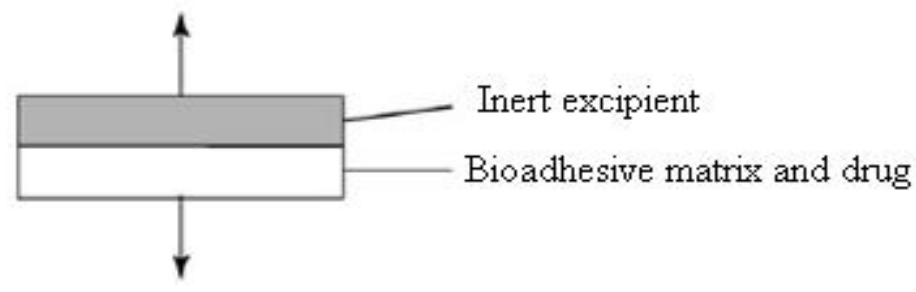

(f)

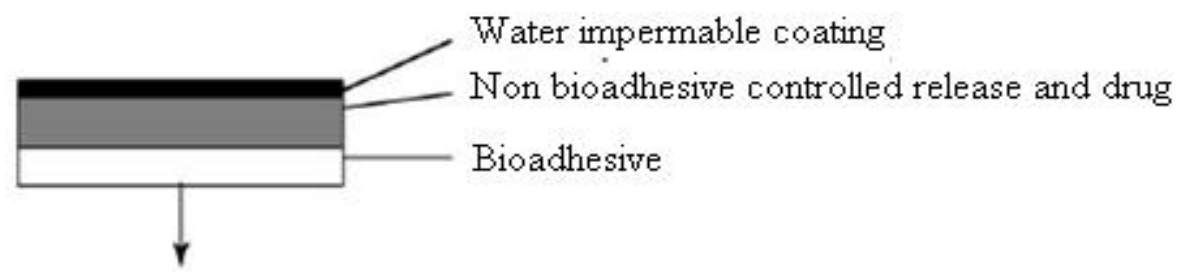

Figure 5: Schematic representation of different types of matrix tablets designed for buccal drug delivery system (Adapted from Caramella and co-workers [108]). 
Amongst the different types of formulation available on the market, solid dosage forms have probably been developed the most extensively such as the nitroglycerin sublingual tablet, fentanyl lozenge on a stick and prochlorperazine buccal tablets. The limitation of these drug delivery systems is the short residence time at site of absorption as depending on the size and type of formulation; they usually dissolved within $30 \mathrm{~min}$, thus limiting the total amount of drug that can be delivered. The dissolution or disintegration of lozenges is usually controlled by the patient, i.e. how hard they suck the unit. Increased sucking and saliva production causes uncontrolled swallowing and loss of drug down the GI tract. Thus, solid dosage forms generally have a much higher inter- and intra-individual variations in absorption and bioavailability. Also such types of system are not able to provide unidirectional release of drug. Continuous secretion of saliva is another major hurdle to the performance of such dosage form.

Minghetti and co-workers [109] proposed the utilisation of clobetasol-17 propionate mucoadhesive tablets for the treatment of oral litchen planus. In this formulation, HPMC and $\mathrm{MgCl}_{2}$ were added into a mucoadhesive polymer matrix, i.e. poly(sodium methacrylate methylmethacrylate), to modify the tablet erosion rate and to obtain drug release over a $6 \mathrm{~h}$ period. A double-blind, controlled study was performed using three groups of patients $(\mathrm{n}=$ 16) who received three applications-a-day over 4 weeks of the developed clobetasol-17 propionate tablets, placebo tablets or a commercial clobetasol-17 propionate ointment for cutaneous application (123 $\mu$ g/application) combined with Orabase ${ }^{\mathrm{TM}}$. The application of 24 $\mu \mathrm{g}$ clobetasol-17 propionate tablet three times a day appeared to be more effective and safer than the semisolid preparation. The addition of $\mathrm{HPMC}$ and $\mathrm{MgCl}_{2}$ in the formulation was thought to effectively control tablet hydration/erosion and, consequently drug release, without significantly modifying mucoadhesion.

Pillay and co-worker [110] reported the use of porosity enabled matrix tablets for the sustained delivery of phenytoin sodium as a model drug. The porosity (pore structure, interconnectors, pore width or diameter, and pore volume of distribution) of the porosity enable matrix formulations had a significant impact on their physicochemical properties. Interphase, co-particulate, co-solvent, homogenization coupled with lyophilization, proved to be efficient methods for construction of the formulation. The optimized formulation displayed the potential to consistently release drug in a steady state, controlled manner over 8 h. Furthermore, the formulation showed the capability to consistently initiate and sustain the permeation of drug through the model buccal mucosal tissue over the period of $8 \mathrm{~h}$. 
The work reported by Kramer and Flynn [111] on pH-solubility profile showed that it is possible to saturate simultaneously unionized and ionized drug species at particular $\mathrm{pH}$ called $\mathrm{pH}_{\max }$ which should lead to an increased transbuccal permeability compared to any other $\mathrm{pH}$. Chow and co-workers [112] explored a $\mathrm{pH}_{\max }$ concept for the sublingual delivery of propanolol. A buffered sublingual propranolol tablet, designed to achieve its $\mathrm{pH}_{\max }$ (when dissolved in saliva), was compared to a marketed product (Inderal ${ }^{\circledR}$ which could not achieve $\left.\mathrm{pH}_{\max }\right)$ in 8 healthy human volunteers. Each subject received the products sublingually for 15 min followed by swallowing the remaining drug in saliva. The plasma propranolol AUC during the first $30 \mathrm{~min}$ from the buffered tablet were significantly higher than that from the Inderal ${ }^{\circledR}$ tablet $(\mathrm{p}<0.05)$. No significant differences in the remaining AUC were observed.

Disks are similar to tablets but are thinner and more flat in shape and can be developed into a different size and shape more suitable to be placed into the buccal cavity. An in vivo evaluation of a buccal disk of cetylpyridinium chloride revealed adequate comfort, taste, nonirritancy and none of the volunteers reported severe dry mouth/severe salivation or heaviness at the place of attachment. Salivary concentrations were maintained above the MIC for $8 \mathrm{~h}$. A good correlation was found between the drug concentration in situ and concentration of drug in saliva collected from healthy human volunteers [113]. A buccal disk of oxycodone hydrochloride was evaluated in healthy human volunteers. The $T_{\max }$ data obtained was greater for the buccoadhesive disks compared to other oral tablets. The fact that the AUC and $C_{\max }$ values were comparable to conventional tablets may have been due to the lack of a backing layer for buccal disk [114]. Thiocochicoside has also been explored for use on the disk type delivery system. An in vivo thiocolchicoside absorption experiments indicated that the fast dissolving sublingual form resulted in a quick uptake of drug within 15 min whereas for the adhesive buccal form the same dose was absorbed over an extended period of time [115].

\subsubsection{Patches/Films/Wafers}

These dosage forms are usually prepared by casting a solution of the polymer, drug and any excipients (such as a plasticiser) on to a surface and allowing it to dry. Patches can be made $10-15 \mathrm{~cm}^{2}$ in size but are more usually $1-3 \mathrm{~cm}^{2}$ with perhaps an ellipsoid shape to fit comfortably into the centre of the buccal mucosa. In a similar fashion to buccal tablets, they can be made multidirectional or unidirectional (e.g., by the application of an impermeable backing layer). They have many of the advantages and disadvantages of buccal tablets, but by being thin and flexible, tend be less obtrusive and more acceptable to the patient. The relative 
thinness of the films, however, means that they are more susceptible to overhydration and loss of the adhesive properties [7].

The major method of polymeric film manufacture is the solvent evaporation process, in which the polymeric material, with or without plasticizer, is dissolved in a solvent or solvent mixture and into which the active constituent is dissolved or dispersed. This solution is then cast onto a suitable substrate and the solvent is allowed to evaporate, leaving a solid polymeric film containing the drug. These types of dosage forms have also been prepared using other techniques such as direct compression and hot-melt extrusion. The advantage associated with these types of techniques was the need organic solvent is avoided and thus it proves to be environment friendly.

The oral cavity mucosa is an ideal surface for the placement of retentive delivery systems such as patches, since it contains a large expanse of smooth and immobile tissue. Mucoadhesive patches for administration to the mucosa of the oral cavity may have a number of different designs, depending on various considerations, such as the therapeutic aim and the physicochemical and pharmacokinetic properties of the active ingredient. Two different rationales for developing mucosal patches may be considered: patches can be intended to deliver a drug to the systemic circulation in a way that is superior to other routes of administration, or their purpose may be local therapy of the oral mucosa [107].

Mucoadhesive buccal patches of lidocaine produced aneasthesia throughout the adhesion period of 60-120 min and the patch was not detached from the buccal mucosa [116]. In a study by Ismail and co-workers [117], it was found that the in vivo release of miconazole was quick but transient from the commercial oral gel Daktarin ${ }^{\circledR}$, which diminished sharply after the first hour of application, compared to buccal patches of miconazole (Figure 6). The optimum patch formulation comprised PVA and PVP and exhibited sustained release over 5 h. Although high drug levels were observed for both formulations during the first $30 \mathrm{~min}$ of the experiment, a remarkable drug concentration was released from the patch after $4 \mathrm{~h}$ compared to traces of the drug obtained from the commercial gel. Detectable drug concentrations were present in saliva even after the complete erosion of the patch (4-4.5 h). The minimum inhibitory concentrations (MIC) for miconazole nitrate against $C$. albicans is 5 $\mu \mathrm{g} / \mathrm{ml} ; T^{>\text {MIC }}$ is the time where the last salivary concentration is above the MIC. The recorded values of $T^{>\text {MIC }}$ were 1.3 and $6.1 \mathrm{~h}$ for Daktarin ${ }^{\circledR}$ oral gel and for mucoadhesive patch, respectively. It is clear that the mucoadhesive patch had a greater ability to sustain an elevated drug concentration in saliva despite the administration of a smaller dose $(10 \mathrm{mg})$ 
compared with the gel $(25 \mathrm{mg})$. In another study in human volunteers by Ismail and coworkers [118], a cetylpyridinum chloride patch made up of chitosan was shown to be superior to a patch made up of hydroxyethyl cellulose and polyvinyl alcohol in terms of in vivo buccal residence time though none of the polymeric patches were detached from the mucosa during the study.

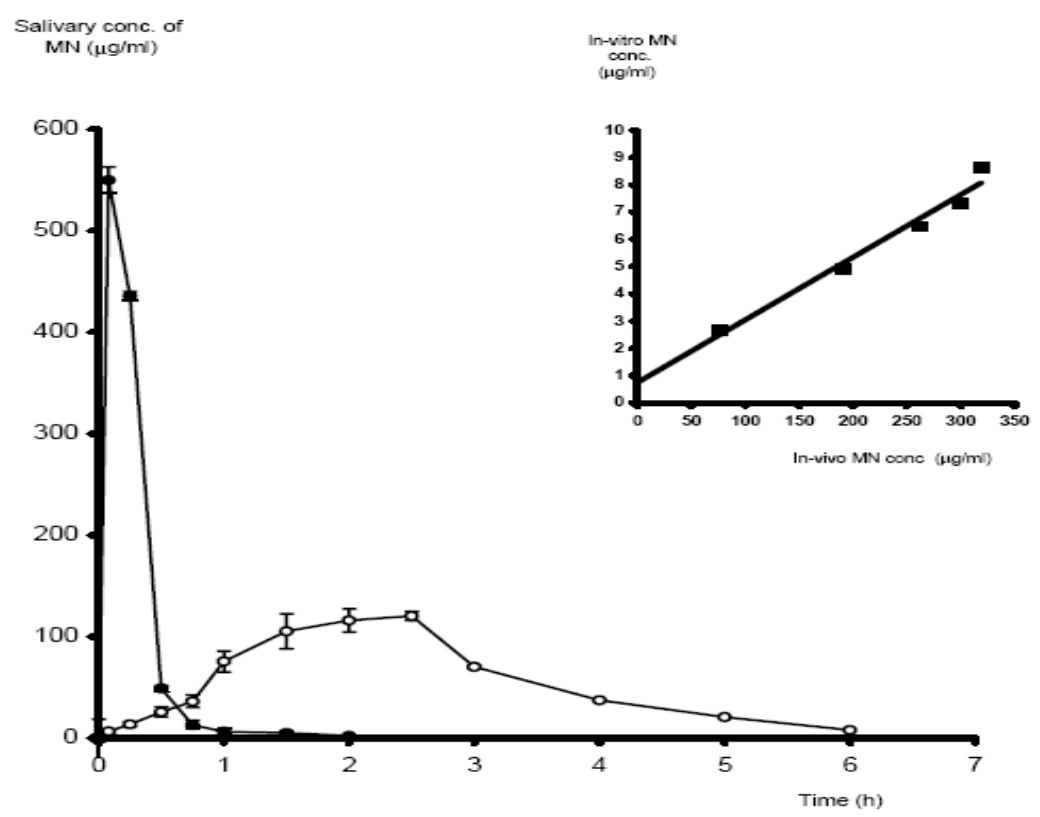

Figure 6: Mean salivary miconazole concentration obtained in vivo with mucoadhesive patch (o) and Daktarin ${ }^{\circledR}$ oral gel $(\bullet)$. The insert represents correlation between in vitro/in vivo cumulative miconazole concentration $(\mu \mathrm{g} / \mathrm{ml})$ released from the mucoadhesive patch [Adapted from ref. 117].

Bilayer films have been evaluated for the mucosal immunization of rabbit via the buccal route. The film consists of two layer and among them one made up of impermeable backing layer while the another layer consists of drug facing towards the mucosa. Efficacy of immunization has been compared by administering the protein injection by subcutaneous route. Postloaded plasmid DNA and $\beta$-lactosidase proteins remained stable after being released from bilayer films. Buccal immunization using novel bilayer films containing plasmid DNA led to comparable antigen-specific IgG titer to that of subcutaneous protein injection. All rabbits immunized with plasmid DNA via the buccal route but none by the subcutaneous route with protein antigen, demonstrated splenocyte proliferative immune responses. The authors concluded that the vaccination without the use of needles would provide a distinct advantage in terms of both cost and safety over conventional vaccines that must be given with needles [119]. 
The current literature shows the research is more focused towards the mucoadhesive type of films or patches which contain different mucoadhesive components to extend the residence time of dosage forms at the site of application. Table 8 shows list of the drugs explored in such mucoadhesive systems.

Table 8: List of few drugs with clinical outcome for films type of buccal drug delivery system

\begin{tabular}{|c|c|c|c|c|c|}
\hline Drug & Polymers & Techniques & $\begin{array}{l}\text { Dosage } \\
\text { Form }\end{array}$ & Clinical outcomes & References \\
\hline Lidocaine $\mathrm{HCl}$ & $\mathrm{EC}, \mathrm{HPC}$ & $\begin{array}{l}\text { Solvent } \\
\text { casting }\end{array}$ & Film & $\begin{array}{l}\text { Effect of drug } \\
\text { observed throughout } \\
\text { adhesion of dosage } \\
\text { form }\end{array}$ & 116 \\
\hline $\begin{array}{l}\text { Miconazole } \\
\text { nitrate }\end{array}$ & $\begin{array}{l}\mathrm{Na} \text { CMC, HEC, } \\
\text { HPMC, PVP }\end{array}$ & $\begin{array}{l}\text { Solvent } \\
\text { casting }\end{array}$ & Film & $\begin{array}{l}\text { Uniform and effective } \\
\text { salivary levels for } \\
\text { atleast } 6 \mathrm{~h}\end{array}$ & 117 \\
\hline $\begin{array}{l}\text { Cetylpyridinum } \\
\text { chloride }\end{array}$ & $\begin{array}{l}\text { PVA, HEC, } \\
\text { chitosan }\end{array}$ & $\begin{array}{l}\text { Solvent } \\
\text { casting }\end{array}$ & Patch & $\begin{array}{l}\text { Increase in residence } \\
\text { time and decrease in } \\
\text { drug release with } \\
\text { storage }\end{array}$ & 118 \\
\hline Acyclovir & $\begin{array}{l}\text { Chitosan } \mathrm{HCl} \text {, } \\
\text { PAA }\end{array}$ & $\begin{array}{l}\text { Solvent } \\
\text { casting }\end{array}$ & Film & $\begin{array}{l}\text { Increase permeation } \\
\text { compared to cream } \\
\text { and suspension }\end{array}$ & 120 \\
\hline Calcitonin & $\begin{array}{l}\text { Noveon AA1, } \\
\text { Eudragit S100 }\end{array}$ & $\begin{array}{l}\text { Solvent } \\
\text { casting }\end{array}$ & $\begin{array}{l}\text { Bilayer } \\
\text { film }\end{array}$ & $\begin{array}{l}\text { Relative } \\
\text { bioavailability of } 43.8 \\
\pm 10.9 \% \text { in rabbit }\end{array}$ & 121 \\
\hline Clotrimazole & HPC, PEO & $\begin{array}{l}\text { Hot melt } \\
\text { extrusion }\end{array}$ & Film & $\begin{array}{l}\text { Excellent content } \\
\text { uniformity and post } \\
\text { processing drug } \\
\text { content of } 93.3 \%\end{array}$ & 122 \\
\hline $\begin{array}{l}\text { Sumatriptan } \\
\text { succinate }\end{array}$ & $\begin{array}{l}\text { Chitosan, gelatin, } \\
\text { PVP }\end{array}$ & $\begin{array}{l}\text { Solvent } \\
\text { casting }\end{array}$ & $\begin{array}{l}\text { Bilayer } \\
\text { patch }\end{array}$ & $\begin{array}{l}\text { No mucosal damage } \\
\text { confirmed by } \\
\text { histopathological } \\
\text { study }\end{array}$ & 123 \\
\hline
\end{tabular}

EC is ethyl cellulose, HPC is hydroxypropyl cellulose, $\mathrm{Na}$ CMC is sodium carboxymethyl cellulose, HEC is hydroxyethyl cellulose, HPMC is hydroxypropyl methylcellulose, PVP is polyvinyl pyrrolidone, PVA is polyvinyl alcohol, PAA is polyacrylic acid and PEO is polyethylene oxide.

\subsubsection{Micro/nano-particulates}

These are typically delivered as an aqueous suspension but can also be applied by aerosol or incorporated into a paste or ointment. Particulates have the advantage of being relatively 
small and, therefore, more likely to be acceptable to the patient. However, the dose of drug retained on the buccal mucosa and, therefore, delivered may not be consistent relative to a single-unit dosage form such as a patch or buccal tablet. Polymeric microparticles (23-38 $\mu \mathrm{m})$ of Carbopol $^{\circledR}$, polycarbophil, chitosan or Gantrez ${ }^{\circledR}$ were found to be capable of adhering to porcine oesophageal mucosa, with particles prepared from the polyacrylic acids exhibiting greater mucoadhesive strength during tensile testing studies whereas, in 'elution' studies, particles of chitosan or Gantrez were seen to persist on mucosal tissue for longer periods of time [124, 125]. Holpuch and co-workers [126] explored the use of nanoparticles for local delivery to the oral mucosa. Two types of nanoparticles were studied in a proof of concept study which were solid lipid nanoparticles incorporating either idarubicin or BODIPY ${ }^{\circledR} \mathrm{FL}$ $\mathrm{C}_{12}$ as model fluorescent probes and polystyrene nanoparticles (FluoSpheres ${ }^{\circledR}$ ) in monolayercultured human oral squamous cell carcinoma (OSCC) cell lines and normal human oral mucosal explants. The results demonstrated that OSCC cells internalized solid lipid nanoparticles. The observed penetration of nanoparticles through the epithelium and basement membrane into the underlying connective tissue suggested the possibility of oral transmucosal nanoparticle delivery for systemic therapy. Monti and co-workers [127] produced an atenolol containing microsphere using Poloxamer 407 and evaluated the formulation in vivo in rabbits against marketed tablet formulation as a reference. After administration of the microsphere formulations, the atenolol concentration remained higher than the reference tablet during the entire elimination phase showing a sustained release profile from the microspheres; the concentrations at $24 \mathrm{~h}$ were $0.75 \pm 0.1 \mu \mathrm{g} / \mathrm{ml}$ vs $0.2 \pm 0.1$ $\mu \mathrm{g} / \mathrm{ml}$ for the microspheres and marketed tablet, respectively. Moreover, the absolute bioavailability of microsphere formulations was higher than that of reference tablets in spite of a lower drug dose in the former, suggesting a possible dose reduction by atenolol microparticles via orotransmucosal administration.

Intra-orally fast-dissolving particles of perphenazine (PPZ) were reported by Laitinen and coworkers [128]. Freeze-drying of solutions of a poorly water soluble drug PPZ with 0\%, 20\%, $80 \%$ or $95 \%$ of a polyethylene glycol (PEG) led to an improved PPZ solubility and extremely fast dissolution rate in a small liquid ( $\mathrm{pH}$ 6.8) volume compared to crystalline or micronized PPZ. The most remarkable improvement in the dissolution rate was seen with 1: 5 ratio of PPZ to PEG, which dissolved within one minute without precipitation of the supersaturated PPZ. A solid dispersion of PPZ with $\beta$-CD prepared by spray drying and with PEG 8000 prepared by freeze drying were compared with micronized PPZ for pharmacokinetic 
parameters in the rabbit after sublingual administration [129]. The value for area under the curve from 0 to $360 \mathrm{~min}\left(A U C_{0-360 \mathrm{~min}}\right)$ of perphenazine after peroral administration was only $8 \%$ compared to the $A U C_{0-360}$ min value obtained after intravenous administration, while the corresponding values for the sublingually administered formulations were $53 \%$ (perphenazine/PEG 8000 solid dispersion), 41\% (perphenazine/ $\beta$-CD complex) and 64\% (micronized perphenazine). These results revealed that the micronized PPZ despite having lower solubility compared to its solid dispersion showed improved plasma concentration. This may have been due to the viscosity enhancing effect of PEG at site of absorption or it may be that the absorption was not solubility or dissolution rate limited.

Liposomes are one of the alternatives for drugs which are poorly soluble and hence are not efficiently delivered from a solid dosage form. For example, silamyrin liposomal buccal delivery showed steady state permeation through a chicken buccal pouch for $6 \mathrm{~h}$ and was higher compared to free drug powder [130].

\subsubsection{Sprays}

An aerosol spray is one of the suitable alternatives to the solid dosage forms and can deliver the drug into the salivary fluid or onto the mucosal surface and thus is readily available for the absorption. As the spray delivers the dose in fine particulates or droplets, the lag time for the drug to be available for the site of the absorption is reduced. For example, a pharmacokinetic study of buccal insulin spray in patient with Type I diabetes revealed no statistical difference in glucose, insulin and C-peptide plasma level compared to insulin administered subcutaneously [131]. In a study by Xu and co-workers [132], insulin delivered through a novel insulin buccal spray was passed through the buccal mucosa promoted by the soybean lecithin and propanediol. Results of rabbit and rat experiments revealed that insulin delivered through the buccal spray is an effective therapeutic alternative to current medication system for treating diabetes. Generex's Oral-lyn ${ }^{\mathrm{TM}}$ is a oral spray for insulin for the treatment of diabetes I and II which is based on the RapidMist ${ }^{\mathrm{TM}}$ technology platform. Generex Oral-lyn ${ }^{\mathrm{TM}}$ is reported to be safe, simple, fast, effective, and pain-free alternative to subcutaneous injections of prandial insulin and is conveniently delivered to the membranes of the oral cavity by a simple asthma-like device with no pulmonary (lung) deposition [133]. Fentanyl citrate, morphine and low molecular weight heparin are also in clinical development based on RapidMist ${ }^{\mathrm{TM}}$ technology by Generex [67]. 


\section{Conclusion}

Due to the ease of access and avoidance of the hepatic metabolism, oral transmucosal drug delivery offers a promising alternative to overcome the limitations of conventional oral drug delivery and parental administration. The buccal and sublingual routes, in particular, present favourable opportunities and many formulation approaches have been explored for such an application; although the current commercially available formulations are mostly limited to tablets and films. Oral mucoadhesive dosage forms will continue be an exciting research focus for improving drug absorption especially for the new generation of the so called 'biologics', although, the palatability and irritancy and formulation retention at the site of application need to be considered in the design of such medicines. 


\section{References:}

1. A.H. Shojaei, Buccal mucosa as a route for systemic drug delivery: a review, J Pharm. Pharmaceut. Sci. 1 (1998) 15-30.

2. R.B. Gandhi, J.R. Robinson, Oral cavity as a site for bioadhesive drug delivery, Adv. Drug Deliv. Rev. 13 (1994) 43-74.

3. N. Salamat-Miller, M. Chittchang, T.P. Johnston, The use of mucoadhesive polymers in buccal drug delivery, Adv. Drug Deliv. Rev. 57 (2005) 1666-1691.

4. M.E. Dowty, K.E. Knuth, B.K. Irons, J.R. Robinson, Transport of thyrotropin releasing hormone in rabbit buccal mucosa in vitro, Pharm. Res. 9 (1992) 1113-1122.

5. J.D. Smart, Lectin-mediated drug delivery in the oral cavity, Adv. Drug Deliv. Rev. 56 (2004) 481-489.

6. L.M.C. Collins, C. Dawes, The surface area of adult human mouth and thickness of salivary film covering the teeth and oral mucosa, J. Dent. Res. 66 (1987) 1300-1302.

7. C.A. Squier, M.J. Kremer, Biology of oral mucosa and esophagus. J. Natl. Cancer Inst. Monogr. 29 (2001) 7-15.

8. J.D. Smart, Buccal drug delivery, Expert Opin. Drug Deliv. 2 (2005) 507-517.

9. M.R. DeFelippis, Overcoming the challenges of noninvasive proteins and peptides delivery, Am. Pharm. Review, 6(2003) 21-30.

10. E.M. Mart1'n del Valle, M.A. Galan, R.G. Carbonell, Drug delivery technologies: The way forward in the new decade, Ind. Eng. Chem. Res. 48 (2009) 2475-2486.

11. F. Gotch, J. Nadell, I.S. Edelman, Gastrointestinal water and electrolytes. IV. The equilibration of deuterium oxide $\left(\mathrm{D}_{2} \mathrm{O}\right)$ in gastrointestinal contents and the proportion of total body water (T.B.W) in the gastrointestinal tract, J. Clin. Invest. 36 (1957) 289-296.

12. J.H. Cummings, J.G. Banwell, I. Segal, N. Coleman, H.N. Englyst, G.T. Macfarlane, The amount and composition of large bowel contents in man, Gastroenterology, 98 (1990) A408.

13. J.L. Herrera, M.F. Lyons, L.F. Johnson, Saliva: its role in health and disease, J. Clin. Gastroenterol. 10 (1988) 569-578.

14. B.L. Slomiany, V.L. Murty, J. Piotrowski, A. Slomiany, Salivary mucins in oral mucosal defence, Gen. Pharmac. 27 (1996) 761-771. 
15. P. Gilles, F.A. Ghazali, J. Rathbone, Systemic oral mucosal drug delivery systems and delivery systems, in: M.J. Rathbone (Ed.), Oral Mucosal Drug Delivery, Vol. 74, Marcel Dekker Inc, New York, 1996, pp. 241-285.

16. C.A. Squier, P. W. Wertz, Structure and function of the oral mucosa and implications for drug delivery, in: M. J. Rathbone (Ed.), Oral Mucosal Drug Delivery, Vol. 74, Marcel Dekker, Inc., New York, 1996, pp. 1-26.

17. I.D. Consuelo, Y. Jacques, G. Pizzolato, R.H. Guy, F. Falson, Comparison of the lipid composition of porcine buccal and esophageal permeability barriers, Arch. Oral Biol. 50 (2005) 981-987.

18. S.P. Humphrey, R.T. Williamson, A review of saliva: normal composition, flow and function, J. Prosthet. Den. 85 (2001) 162-169.

19. M.E. de Vries, H.E. Bodde, J.C. Verhoef, H.E. Junginger, Developments in buccal drug delivery, Crit. Rev. Ther. Drug Carrier Syst. 8 (1991) 271-303.

20. B. Li, J.R. Robinson. Preclinical assessment of oral mucosal drug delivery systems, In: T.K. Ghosh, W.R. Pfister, eds. Drug delivery to the oral cavity: Molecules to market, Boca Raton, FL: CRC Press, 2005, pp. 41-66.

21. C.A. Squier, D. Nanny, Measurement of blood flow in the oral mucosa and skin of the rhesus monkey using radiolabelled microspheres, Arch. Oral Biol. 30 (1985)313-318.

22. H. Sohi, A. Ahuja, F.J. Ahmad and R. K. Khar, Critical evaluation of permeation enhancers for oral mucosal drug delivery, Drug Dev. Ind. Pharm. 36 (2010) 254-282.

23. D. Harris, J.R. Robinson, Drug delivery via the mucous membranes of the oral cavity, J. Pharm. Sci. 81 (1992) 1-10.

24. W.R. Galey, H.K. Lonsdale, S. Nacht, The in vitro permeability of skin and buccal mucosa to selected drugs and tritiated water, J. Invest. Dermatol. 67 (1976) 713-717.

25. A.F. Hayward, Membrane-coating granules, Int. Rev. Cyt. 59 (1979) 97-127.

26. C.A. Squier, R.A. Eady, R.M. Hopps, The permeability of epidermis lacking normal membrane-coating granules: an ultrastructural tracer study of Kyrle-Flegel disease, J. Invest. Dermatol. 70 (1978) 361-364.

27. C.A. Squier, B.K. Hall, The permeability of mammalian nonkeratinized oral epithelia to horseradish peroxidise applied in vivo and in vitro, Arch. Oral Biol. 29 (1984) 4550.

28. A. Allen, The gastrointestinal physiology. Salivary, gastric and hepatobiliary secretions, in: J.G. Forte (Ed.), Handbook of Physiology, Vol. III Section 6, American Physiological Society, Bethesda, MD, 1989, pp. 359-382. 
29. D.A. Norris, N. Puri, P.J. Sinko, The effect of physical barriers and properties on the oral absorption of particulates, Adv. Drug Deliv. Rev. 34 (1998) 135-154.

30. P. Bures, Y. Huang, E. Oral, N.A. Peppas, Surface modifications and molecular imprinting of polymers in medical and pharmaceutical applications, J. Control. Release, 72 (2001) 25-33.

31. M. Rathbone, B. Drummond, I. Tucker, Oral cavity as a site for systemic drug delivery, Adv. Drug Del. Rev. 13 (1994) 1-22.

32. M.R. Castellanos, H. Zia, C.T. Rhodes, Mucoadhesive drug delivery systems, Drug Dev. Ind. Pharm. 19 (1993) 143-194.

33. E.L. McConnell, H.M. Fadda, A.W. Basit, Gut instincts: explorations in intestinal physiology and drug delivery, Int. J. Pharm. 364 (2008) 213-226.

34. E.L. McConnell, F. Lui, A.W. Basit, Colonic treatment and targets: issues and opportunities, J. Drug Target. 17 (2009) 335-363.

35. S.I. Pather, M.J. Rathbone, S. Senel, Current status and the future of buccal drug delivery systems, Expert Opin. Drug Deliv. 5 (2008) 531-542.

36. H.M. Nielsen, M.R. Rassing, TR146 cells grown on filters as a model of human buccal epithelium: V. Enzyme activity of the TR146 cell culture model, human buccal epithelium and porcine buccal epithelium, and permeability of leu-enkephalin, Int. J. Pharm. 200 (2000) 261-270.

37. G.F. Walker, N. Langoth, A. Bernkop-Schnurch, Peptidase activity on the surface of the porcine buccal mucosa, Int. J. Pharm. 233 (2002) 141-147.

38. C.A. Lesch, C.A. Squier, A. Cruchley, D.M. Williams, P. Speight, The permeability of human oral mucosa and skin to water, J. Dent. Res. 68 (1989) 1345-1349.

39. C.A. Squier, B.K. Hall, The permeability of the skin and oral mucosa to water and horseradish peroxidise as related to the thickness of the permeability barrier, The J. Inv. Dermat. 84 (1985) 176-179.

40. R. Mahalingam, H. Ravivarapu, S. Redkar, X. Li and B.R. Jasti, Transbuccal delivery of 5-Aza-2'-Deoxycytidine: effects of drug concentration, buffer solution and bile salts on permeation, AAPS PharmSciTech, 8 (2007) Article 55, E1-E6.

41. J. Xiang, X. Fang, X. Li, Transbuccal delivery of 2', 3'-dideoxycytidine: in vitro permeation study and histological investigation, Int. J. Pharm. 231(2002)57-66.

42. V.H.M. Deneer, G.B. Drese, P.E.H. Roemele, J.C. Verhoef, L. Lie-A-Huen, J.H. Kingma, J.R.B.J. Brouwers, H.E. Junginger, Buccal transport of flecainide and sotalol: effect of a bile salt and ionization state, Int. J. Pharm. 241 (2002) 127-134. 
43. H.M. Nielsen, M.R. Rassing, Nicotine permeability across the buccal TR146 cell culture model and porcine buccal mucosa in vitro: effect of $\mathrm{pH}$ and concentration, Eur. J. Pharm. Sci. 16 (2002) 151-157.

44. R. Mashru, V. Sutariya, M. Sankalia, J. Sankalia, Transbuccal delivery of lamotrigine across porcine buccal mucosa: in vitro determination of routes of buccal transport, J. Pharm. Pharmaceut. Sci. 8 (2005) 54-62.

45. Y. Kurosaki, K. Yano, T. Kimura, Perfusion cells for studying regional variation in oral mucosal permeability in humans. 2. A specialized transport mechanism in Dglucose absorption across cultured dorsum of tongue. J. Pharm. Sci. 87 (1998) 613615.

46. T. Kimura, H. Yamano, A. Tanaka, T. Matsumara, M. Ueda, K. Ogawara, Transport of D-glucose across cultured stratified cell layer of human oral mucosal cells. J. Pharm. Pharmacol. 54 (2002) 213-219.

47. V. De Caro, G. Giandalia, M.G. Siragusa, C. Paderni, G. Campisi, L.I. Giannola, Evaluation of galantamine transbuccal absorption by reconstituted human oral epithelium and porcine tissue as buccal mucosa models: Part I, Eur. J. Pharm. Biopharm. 70 (2008) 869-873.

48. L.I. Giannola, V. De Caro, G. Giandalia, M.G. Siragusa, C. Tripodo, A.D. Florena, G. Campisi, Release of naltrexone on buccal mucosa: Permeation studies, histological aspects and matrix system design, Eur. J. Pharm. Biopharm. 67(2007) 425-433.

49. R. Birudaraj, B. Berner, S. Shen, X. Li, Buccal permeation of buspirone: Mechanistic studies on transport pathways, J. Pharm. Sci. 94(2005) 70-78.

50. R.C. Mashru, V.B. Sutariya, M.G. Sankalia, and J.M. Sankalia, Effect of pH on in vitro permeation of ondansetron hydrochloride across porcine buccal mucosa, Pharm. Dev. Tech. 10 (2005) 241-247.

51. N. Utoguchi, Y. Watanabe, T. Suzuki, J. Maehara, Y. Matsumoto, M. Matsumoto, Carrier-mediated transport of monocarboxylic acids in primary cultured epithelial cells from rabbit oral mucosa, Pharm. Res. 14 (1997) 320-324.

52. N. Utoguchi, Y. Watanabe, T. Suzuki, J. Maehara, Y. Matsumoto, M. Matsumoto, Carrier-mediated absorption of salicylic acid from hamster cheek pouch mucosa, J. Pharm. Sci. 88 (1999) 142-146.

53. Y. Oyama, H. Yamano, A. Ohkuma, K. Ogawara, K. Higaki, T. Kimura, Carriermediated transport systems for glucose in mucosal cells of the human oral cavity, J. Pharm. Sci. 88 (1999) 830-834. 
54. Y. Sudhakar, K. Kuotsu and A.K. Bandyopadhyay, Buccal bioadhesive drug delivery - a promising option for orally less efficient drugs, J. Control. Rel. 114 (2006)15-40.

55. http://www.intelgenx.com/technologies/quickreleasewafer.html, accessed on 02/03/2010.

56. http://www.bioenvelop.com/english/prd_technology.html, accessed on 02/03/2010.

57. http://www.innozen.com, accessed on 02/03/2010.

58. http://www.biofilm.co.uk/cms/index.php?option=com_content\&view=article\&id=23 $\&$ Itemid $=69$, accessed on 02/03/2010.

59. http://www.meldexinternational.com/technology_platforms.asp, accessed on $02 / 03 / 2010$.

60. http://www.meldexinternational.com/pages/content/index.asp?PageID=50, accessed on $02 / 03 / 2010$.

61. http://www.meldexinternational.com/pages/content/index.asp?PageID=48, accessed on $02 / 03 / 2010$.

62. http://www.uluruinc.com/oradisc_a.htm, accessed on 02/03/2010.

63. http://www.monosolrx.com/technology_thinfilm.html, accessed on 02/03/2010.

64. http://www.monosolrx.com/rx_develop.html, accessed on 02/03/2010.

65. http://www.snoreeze.com/the-snoreeze-range/snoreeze-oral-strips, accessed on 03/03/2010.

66. http://www.gwpharm.com/Sativex.aspx, accessed on 03/03/2010.

67. http://www.generex.com/technology.php, accessed on 30/03/2010.

68. http://www.novadel.com/pipeline/index.htm, accessed on 30/03/2010

69. http://www.biodeliverysciences.com/BEMA.php, accessed on 03/03/2010.

70. http://www.biodeliverysciences.com/pipeline.php, accessed on 30/03/2010.

71. http://www.transcept.com/content/view/39/95/, accessed on 30/03/2010.

72. http://www.biodeliverysciences.com/BEMA_Buprenorphine.php, accessed on 03/03/2010.

73. http://www.biodeliverysciences.com/pipeline.php, accessed on 03/03/2010.

74. http://www.labtec-pharma.com/index.php?article_id=24, accessed on 03/03/2010.

75. http://www.labtec-pharma.com/index.php?article_id=24, accessed on 03/03/2010.

76. http://www.medpharm.co.uk

77. H.H. Alur, J.D. Beal, S.I. Pather, A.K. Mitra, T.P. Johnston, Evaluation of a novel, natural oligosaccharide gum as a sustained-release and mucoadhesive component of calcitonin buccal tablets, J. Pharm. Sci. 88 (1999) 1313-1319. 
78. C.R. Lopez, A. Portero, J.L. Vila-Jato, M.J. Alonso, Design and evaluation of chitosan/ethylcellulose mucoadhsive bilayered devices for buccal drug delivery. J. Contol. Rel. 55(1998)143-152.

79. J.W. Lee, J.H. Park, J.R. Robinson, Bioadhesive-based dosage forms: the next generation. J. Pharm. Sci. 89 (2000) 850-866.

80. J.D. Smart, The basics and underlying mechanisms of mucoadhesion, Adv. Drug Deliv. Rev. 57 (2005) 1556-1568.

81. G.P. Andrews, T.P. Laverty, D.S. Jones, Mucoadhesive polymeric platforms for controlled drug delivery, Eur. J. Pharm. Biopharm. 71 (2009) 505-518.

82. F. Madsen, K. Eberth, J. Smart, A rheological assessment of the nature of interactions between mucoadhesive polymers and a homogenised mucus gel, Biomaterials 19 (1998) 1083-1092.

83. M.I. Ugwoke, R.U. Agu, N. Verbeke, R. Kinget, Nasal mucoadhesive drug delivery: background, applications, trends and future perspectives, Adv. Drug Deliv. Rev. 57 (2005) 1640-1665.

84. D. Dodou, P. Breedveld, P. Wieringa, Mucoadhesives in the gastrointestinal tract: revisiting the literature for novel applications, Eur. J. Pharm. Biopharm. 60 (2005) 116.

85. A. Ahagon, A.N. Gent, Effect of interfacial bonding on the strength of adhesion, J. Polym. Sci. Polym. Phys. 13 (1975) 1285-1300.

86. M.R. Jiménez-Castellanos, H. Zia, C.T. Rhodes, Mucoadhesive drug delivery systems, Drug Dev. Ind. Pharm. 19 (1993) 143-194.

87. J.W. Lee, J.H. Park, J.R. Robinson, Bioadhesive-based dosage forms: the next generation, J. Pharm. Sci. 89 (2000) 850-866.

88. A. Shojaei, X. Li, Mechanisms of buccal mucoadhesion of novel copolymers of acrylic acid and polyethylene glycol monomethylether monomethacrylate, J. Control. Rel. 47 (1997) 151-161.

89. A. Ludwig, The use of mucoadhesive polymers in ocular drug delivery, Adv. Drug Deliv. Rev. 57 (2005) 1595-1639.

90. N. Fefelova, Z. Nurkeeva, G. Mun, V. Khutoryanskiy, Mucoadhesive interactions of amphiphilic cationic copolymers based on [2- (methacryloyloxy) ethyl] trimethyl ammonium chloride, Int. J. Pharm. 339 (2007) 25-32.

91. P. He, S. Davis, L. Illum, In vitro evaluation of the mucoadhesive properties of chitosan microspheres, Int. J. Pharm. 166 (1998) 75-88. 
92. A. Portero, D. Teijeiro-Osorio, M. Alonso, C. Remuñán-López, Development of chitosan sponges for buccal administration of insulin, Carbohydr. Polym. 68 (2007) 617-625.

93. S. Rossi, F. Ferrari, M. Bonferoni, C. Caramella, Characterization of chitosan hydrochloride-mucin interaction by means of viscosimetric and turbidimetric measurements, Eur. J. Pharm. Sci. 10 (2000) 251-257.

94. A. Bernkop-Schnürch, Chitosan, its derivatives: potential excipients for peroral peptide delivery systems, Int. J. Pharm. 194 (2000) 1-13.

95. M.A. Clark, B. Hirst, M. Jepson, Lectin-mediated mucosal delivery of drugs and microparticles, Adv. Drug Deliv. Rev. 43 (2000) 207-223.

96. V. Leitner, G. Walker, A. Bernkop-Schnürch, Thiolated polymers: evidence for the formation of disulphide bonds with mucus glycoproteins, Eur. J. Pharm. Biopharm. 56 (2003) 207-214.

97. K. Albrecht, M. Greindl, C. Kremser, C. Wolf, P. Debbage, A. Bernkop-Schnürch, Comparative in vivo mucoadhesion studies of thiomer formulations using magnetic resonance imaging and fluorescence detection, J. Control. Rel. 115 (2006) 78-84.

98. M. Roldo, M. Hornof, P. Caliceti, A. Bernkop-Schnürch, Mucoadhesive thiolated chitosans as platforms for oral controlled drug delivery: synthesis and in vitro evaluation, Eur. J. Pharm. Biopharm. 57 (2004) 115-121.

99. D. Patel, A.W. Smith, N. Grist, P. Barnett, J.D. Smart, In-vitro mucosal model predictive of bioadhesive agents in the oral cavity. J. Control. Rel. 61(1999) 175-183.

100. J. Jacobsen, Buccal iontophoretic delivery of atenolol $\mathrm{HCl}$ employing a new in vitro three-chamber permeation cell, J. Control. Rel. 70 (2001) 83-95.

101. G. Campisi, L.I. Giannola, A.M. Florena, V. De Caro, A. Schumacher, T. Göttsche, C. Paderni, A. Wolff, Bioavailability in vivo of naltrexone following transbuccal administration by an electronically-controlled intraoral device: A trial on pigs, J. Control. Rel. 145 (2010) 214-220.

102. L. Martin, C.G. Wilson, F. Koosha, I.F. Uchegbu, Sustained buccal delivery of the hydrophobic drug denbufylline using physically cross-linked palmitoyl glycol chitosan hydrogels, Euro. J. Pharm. Biopharm. 55 (2003) 35-45.

103. I.G. Needleman, Controlled drug release in periodontics: a review of new therapies, Bri. Dent. J. 170 (1991) 405-408. 
104. D.S. Jones, A.D. Woolfson, J. Djokic, W.A. Coulter, Development and mechanical characterization of bioadhesive semi-solid, polymeric systems containing tetracycline for the treatment of periodontal diseases, Pharm. Res. 13 (1996) 1734-1738.

105. L.B. Heemstra, B.C. Finnin, J.A. Nicolazzo, The buccal mucosa as an alternative route for the systemic delivery of risperidone, J. Pharm. Sci. 99 (2010) 4584-4592.

106. L. Perioli, C. Pagano, S. Mazzitelli, C. Rossi, C. Nastruzzi, Rheological and functional characterization of new anti-inflammatory delivery systems designed for buccal administration, Int. J. Pharm. 356 (2008) 19-28.

107. M. L. Bruschi, O. de Freitas, Oral bioadhesive drug delivery systems, Drug Dev. Ind. Pharm. 31 (2005) 293-310.

108. S. Rossi, G. Sandri, C.M. Caramella, Buccal drug delivery: A challenge already won? Drug Dis. Today: Technologies, 2(2005) 59-65.

109. F. Cilurzo, C.G.M. Gennari, F. Selmin, J.B. Epstein, G.M. Gaeta, G. Colella, P. Minghetti, A new mucoadhesive dosage form for the management of oral lichen planus: Formulation study and clinical study, Euro. J. Pharm. Biopharm. 76 (2010) 437-442.

110. O.A. Adeleke, V. Pillay, L.C. du Toit, Y.E. Choonara, Construction and in vitro characterization of an optimized porosity-enabled amalgamated matrix for sustained transbuccal drug delivery, Int. J. Pharm. 391 (2010) 79-89.

111. S.F. Kramer, G.L. Flynn, Solubility of organic hydrochlorides, Pharm. Res. 61 (1972) 1896-1904.

112. Y. Wang, Z. Zuo, X. Chen, B. Tomlinson, M.S.S. Chow, Improving sublingual delivery of weak base compounds using $\mathrm{pH}_{\max }$ concept: Application to propranolol, Euro. J. Pharm. Sci. 39 (2010) 272-278.

113. J. Ali, R. Khar, A. Ahuja, R. Kalra, Buccoadhesive erodible disk for treatment of orodental infections: design and characterisation, Int. J. Pharm. 283 (2002) 93-103.

114. B. Parodi, E. Russo, G. Caviglioli, M. Vallarino, F. Fusco, F. Henriquet, Buccoadhesive oxycodone hydrochloride disks: plasma pharmacokinetics in healthy volunteers and clinical study, Eur. J. Pharm. Biopharm. 44 (1997)137-142.

115. M. Artusi, P. Santi, P. Colombo, H.E. Junginger, Buccal delivery of thiocolchicoside: in vitro and in vivo permeation studies, Int. J. Pharm. 250 (2003) 203-213.

116. Y. Kohda, H. Kobayashi, Y. Baba, H. Yuasa, T. Ozeki, Y. Kanaya, E. Sagara, Controlled release of lidocaine hydrochloride from buccal mucosa-adhesive films with solid dispersion, Int. J. Pharm. 158 (1997)147-155. 
117. N.A. Nafee, F.A. Ismail, N.A. Boraie, L.M. Mortada, Mucoadhesive buccal patches of miconazole nitrate: in vitro/in vivo performance and effect of ageing, Int. J. Pharm. 264 (2003) 1-14.

118. N.A. Nafee, F.A. Ismail, N.A. Boraie, L.M. Mortada, Design and characterization of mucoadhesive buccal patches containing cetylpyridinium chloride, Acta Pharm. 53 (2003) 199-212.

119. Z. Cui, R.J. Mumper, Bilayer films for mucosal (genetic) immunization via the buccal route in rabbits, Pharm. Res. 19 (2002) 947-953.

120. S. Rossi, G. Sandri, F. Ferrari, M.C. Bonferoni, C. Caramella, Buccal delivery of acyclovir from films based on chitosan and polyacrylic acid, Pharm. Dev. Tech. 8 (2003) 199-208.

121. Z. Cui, R.J. Mumper, Buccal transmucosal delivery of calcitonin in rabbits using thinfilm composites, Pharm. Res. 19 (2002) 1901-1906.

122. M.A. Repka, S. Prodduturi S.P. Stodghill, Production and characterization of hot-melt extruded films containing clotrimazole, Drug Dev. Ind. Pharm. 29 (2003) 757-765.

123. S.S. Shidhaye, N.S. Saindane, S. Sutar, V. Kadam, Mucoadhesive bilayered patches for administration of sumatriptan succinate, AAPS PharmSciTech. 9 (2008) 909-916.

124. S. Kockisch, G.D. Rees, S.A. Young, J. Tsibouklis, J.D. Smart, Polymeric microspheres for drug delivery to the oral cavity: an in vitro evaluation of mucoadhesive potential, J. Pharm. Sci. 92 (2003) 1614-1623.

125. S. Kockisch, G.D. Rees, S.A. Young, J. Tsibouklis, J.D. Smart, In-situ evaluation of drug-loaded microspheres on a mucosal surface under dynamic test conditions, Int. J. Pharm. 276 (2004) 51-58.

126. A.S. Holpuch, G.J. Hummel, M.Tong, G.A. Seghi, P. Pei, P. Ma, R.J. Mumper, S.R. Mallery, Nanoparticles for local drug delivery to the oral mucosa: Proof of principle studies, Pharm. Res. 27(2010) 1224-1236.

127. D. Monti, S. Burgalassi, M.S. Rossato, B. Albertini, N. Passerini, L. Rodriguez, P. Chetoni, Poloxamer 407 microspheres for orotransmucosal drug delivery. Part II: In vitro/in vivo evaluation, Int. J. Pharm. 400 (2010) 32-36.

128. R. Laitinen, E. Suihko, K. Toukola, M. Björkqvist, J. Riikonen, V. Lehto, K. Järvinen, J. Ketolainen, Intraorally fast-dissolving particles of a poorly soluble drug: Preparation and in vitro characterization, Euro. J. Pharm. Biopharm. 71 (2009) 271281. 
129. E. Turunen, J. Mannila, R. Laitinen, J. Riikonen, V. Lehto, T. Järvinen, J. Ketolainen, K. Järvinen, P. Jarho, Fast-dissolving sublingual solid dispersion and cyclodextrin complex increase the absorption of perphenazine in rabbits, J. Pharm. Pharmaco., 16 NOV 2010, DOI 10.1111/j.2042-7158.2010.01173.x

130. M.S. El-Samaligy, N.N. Afifi, E.A. Mahmoud, Increasing bioavailability of silymarin using a buccal liposomal delivery system: Preparation and experimental design investigation, Int. J. Pharm. 308 (2006) 140-148.

131. P. Pozzilli, S. Manfrini, F. Costanza, G. Coppolino, M.G. Cavallo, E. Fioriti, P. Modi, Biokinetics of buccal spray insulin in patients with type 1 diabetes, Metabol. Clin. Exp. 54 (2005) 930-934.

132. H. Xu, K. Huang, Y. Zhu, Q. Gao, Q. Wu, W. Tian, X. Sheng, Z. Chen, Z. Gao, Hypoglycaemic effect of a novel insulin buccal formulation on rabbits, Pharmacol. Res. 46 (2002) 459-467.

133. http://www.generex.com/products.php?prod_id=Nzk=, accessed on 23/11/2010. 